\title{
Morphological characterization and staging of bumble bee pupae
}

Li Tian ${ }^{1}$, Heather M Hines ${ }^{\text {Corresp. } 1}$

${ }^{1}$ Department of Biology, Pennsylvania State University, University Park, PA, United States

Corresponding Author: Heather M Hines

Email address: hmh19@psu.edu

Bumble bees (Hymenoptera: Apidae, Bombus) are important pollinators and models for studying mechanisms underlying developmental plasticity, such as factors influencing size, immunity, and social behaviors. Research on such processes, as well as expanding use of gene-manipulation and gene expression technologies, requires a detailed understanding of how these bees develop. Developmental research often uses time-staging of pupae, however dramatic size differences in these bees can generate variation in developmental timing. To study developmental mechanisms in bumble bees, appropriate staging of developing bees using morphology is necessary. In this study, we describe morphological changes across development in several bumble bee species and use this to establish morphology-based staging criteria, establishing 20 distinct illustrated stages. These criteria, defined largely by eye and cuticle pigmentation patterns, are generalizable across members of the subgenus Pyrobombus, and can be used as a framework for study of other bumble bee subgenera. We examine the effects of temperature, caste, size, and species on pupal development, revealing that pupal duration shifts with each of these factors, confirming the importance of staging pupae based on morphology rather than age and the need for standardizing sampling. 
1 Morphological characterization and staging of bumble bee

2 pupae

3

4 Li Tian $^{1}$, Heather M. Hines ${ }^{1}$

5

$6{ }^{1}$ Department of Biology, Pennsylvania State University, University Park, PA, USA

7

8 Corresponding Author:

9 Heather M. Hines ${ }^{1}$

10517 Mueller Laboratory, University Park, PA 16802, USA

11 Email address: hmh19@psu.edu.

12

13

14

15

16

17

18

19

20

21

22

23

24

25

26

27

28

29

30

31

32

33

34

35 


\section{ABSTRACT}

37

38

39

40

41

42

43

44

45

46

47

48

49

50

51

52

53

54

55

56

57

58

59

60

61

62

63

64

65

66

67

Bumble bees (Hymenoptera: Apidae, Bombus) are important pollinators and models for studying mechanisms underlying developmental plasticity, such as factors influencing size, immunity, and social behaviors. Research on such processes, as well as expanding use of gene-manipulation and gene expression technologies, requires a detailed understanding of how these bees develop.

Developmental research often uses time-staging of pupae, however dramatic size differences in these bees can generate variation in developmental timing. To study developmental mechanisms in bumble bees, appropriate staging of developing bees using morphology is necessary. In this study, we describe morphological changes across development in several bumble bee species and use this to establish morphology-based staging criteria, establishing 20 distinct illustrated stages. These criteria, defined largely by eye and cuticle pigmentation patterns, are generalizable across members of the subgenus Pyrobombus, and can be used as a framework for study of other bumble bee subgenera. We examine the effects of temperature, caste, size, and species on pupal development, revealing that pupal duration shifts with each of these factors, confirming the importance of staging pupae based on morphology rather than age and the need for standardizing sampling.

\section{INTRODUCTION}

The primitively eusocial bumble bees are important pollinators and fascinating models for studying developmental plasticity and adaptive variation. Bumble bees contain social castes that engage in division of labor among queens and workers. Social individuals in the nest can differ dramatically in body size, with queens being substantially and discretely larger than workers, and workers exhibiting dramatic plasticity in size, including up to 10-fold size variation (Couvillon et al., 2010). Individual size and related social function are influenced by sensitive periods in development to various environmental factors, such as nutrition, temperature and pheromones (Groh, Tautz \& Rössler, 2004; Plowright \& Jay, 1968; Sakagami, Akahira \& Zucchi, 1967; Tautz et al., 2003). Deciphering genetic and developmental processes behind these phenotypes remains an active area of inquiry (Cnaani, Robinson \& Hefetz, 2000; Couvillon \& Dornhaus, 2009; Li et al., 2018; Pereboom et al., 2005; Tasei \& Aupinel, 2008). New genetic technologies increasingly enable the targeting of genes and their functions in non-model organisms. In bumble 
68 bees this expands the potential for uncovering the genetic mechanisms underlying a variety of

69 evolutionarily interesting traits, such as traits related to caste differentiation (Price et al., 2018),

70 foraging and social behavior, thermoregulation, diapause (Amsalem et al., 2015), coloration

71 (Rapti, Duennes \& Cameron, 2014), and pollination-relevant morphologies (Medved, Huang \&

72 Popadić, 2014). The search for gene function has led to the increasing need to assess and modify

73 genes during development. For example, RNAi methods are applied throughout developmental

74 stages to characterize gene function in the bees (Brutscher \& Flenniken, 2015; Cridge et al., 75 2017; Hu et al., 2010; Medved, Huang \& Popadić, 2014) and many other insects (Bellés, 2010;

76 Gu \& Knipple, 2013), and gene expression studies involve standardization of samples to specific

77 developmental stages (Chen et al., 2012; Collins et al., 2017; Jones, Wcislo \& Robinson, 2015;

78 Pereboom et al., 2005).

79

80

Comparative study of these traits requires a detailed understanding of developmental processes. Larval development has been examined fairly closely in bumble bees. Four larval instars have been determined in Bombus terrestris and Bombus impatiens based on frequency distributions of head capsule widths for queen and worker larvae (Cnaani et al., 1997; Cnaani,

84 Schmid-Hempel \& Schmidt, 2002). Finer staging of larval stages has involved categorizing 85 larval instars by weight group (Cnaani, Robinson \& Hefetz, 2000) and larval duration of 86 different castes has been determined in several species (Cnaani, Robinson \& Hefetz, 2000;

87 Cnaani, Schmid-Hempel \& Schmidt, 2002; Sakagami, Akahira \& Zucchi, 1967). The 88 development of bumble bee pupae is less understood. In general, pupation in bumble bees is 89 similar to other bees (Michener, 2000) and many holometabolous insects (Gillott, 1991). It starts 90 when a pre-pupa sheds the larval cuticle, a process known as larva-pupal ecdysis. The pupa then 91 undergoes apolysis, in which the newly developed adult epidermis begins to separate from the 92 pupal cuticle, marking the beginning of the pharate adult stage (Elias-Neto, Soares \& Bitondi, 93 2009). The end of the pupa stage is marked by molting of pupal cuticle, known as pupal-adult 94 ecdysis, followed by the eclosion of the young adult, termed the callow, from the cocoon. Unlike in larvae, detailed descriptions of the changes during pupal development are lacking. 96 
99 in a few studies on bumble bees (Bortolotti, Duchateau \& Sbrenna, 2001; Dean, 2016; Ribeiro, 100 1994), however, given that developmental timing may vary by size, caste and environmental 101 conditions (Cnaani et al., 1997; Sakagami, Akahira \& Zucchi, 1967; Sutcliffe \& Plowright, 102 1990), morphology-based staging criteria is likely to be a more reliable way to establish 103 developmentally homologous stages in these bees. Seven generalized pupal stages based on 104 pigmentation of the thorax and the compound eyes are recognized in the honey bee Apis mellifera (Michelette \& Soares, 1993; Rembold, Kremer \& Ulrich, 1980). These staging criteria have been extended to studies on other bee species, with little or no modifications (CardosoJúnior et al., 2017; Hartfelder \& Rembold, 1991;Thorp, 1969;Cruz-Landim \& Mello, 1967; Daly, 1966). In only a few bee species, including $A$. mellifera and a stingless bee Melipona scutellaris, are keys and images available for pupal stages (Cardoso-Júnior et al., 2017; Daly, 1966; Elias-Neto, Soares \& Bitondi, 2009). Thus far attempts to separate bumble bee pupa by morphology has involved either using a modification of the same six stages for honey bees or a more simplified model (Dong et al., 2017; Li et al., 2010; Mänd et al., 2005). Morphological keys from other species like honey bees are not enough to represent fine increments of pupal development in bumble bees needed for developmental genetic work.

In the present study, we provide a detailed profile and illustrated key of morphological changes during bumble bee pupal development as a reference for future developmental research. In addition to commonly used traits like the compound eyes and thoracic color, we document slight changes in morphological structure in various body parts including face, , appendages and ommatidia. Our key includes 20 distinct and maximally informative stages covering the full duration and regular increments of pupal development, built from comparisons among three bumble bee species of the bumble bee subgenus Pyrobombus.

As part of this assessment, we also test how environmental and physiological factors affect pupal duration and influence the length of individual stages. The pupal phase comprises a third of the duration of the immature stage of a bumble bee (Cnaani, Robinson \& Hefetz, 2000; Cnaani, Schmid-Hempel \& Schmidt, 2002 ), but can vary in duration due to multiple factors. Pupal duration may vary by caste, as $B$. terrestris and $B$. impatiens queen pupae have been shown to develop for four days longer than workers (Cnaani, Robinson \& Hefetz, 2000; Cnaani, 
130 Schmid-Hempel \& Schmidt, 2002). Body size is also likely to affect pupal duration as larger 131 bees were observed to take longer to develop than smaller bees in Bombus atratus (Sakagami, 132 Akahira \& Zucchi, 1967) and Bombus terricola (Sutcliffe \& Plowright, 1990). Nutrition can also 133 play a role, as pupae from colonies with more access to pollen have longer pupal duration 134 (Sutcliffe \& Plowright, 1990). A negative correlation between temperature and pupal period has 135 been implied in bumble bees, as reduced temperature decreased colony growth rate in $B$. 136 impatiens and Bombus affinis (Vogt, 1986b). Similarly, Cartar \& Dill (1991) observed that 137 cooling cocoons of Bombus occidentalis and Bombus melanopygus for a short period delayed 138 median adult eclosion time. To add to our understanding of developmental plasticity in pupal 139 duration, and better inform the effects of environmental factors on pupal staging, we specifically 140 test the effect of caste, sex, body size, temperature, and species on pupal duration.

\section{MATERIALS \& METHODS}

\section{Bumble bees}

145 In this study, we examined and compared pupal as well as early adult development in both 146 commercial and wild reared colonies of the eastern Nearctic bumble bee Bombus impatiens 147 Cresson and in two other wild-reared Pyrobombus species from the western Nearctic, Bombus melanopygus Nylander and Bombus vosnesenskii Radoszkowski. Commercial colonies of $B$. impatiens were obtained from Koppert Biological Systems (Howell, MI, U.S.A.) and maintained prior to study under laboratory conditions $\left(25^{\circ} \mathrm{C}, 50 \% \mathrm{RH}\right.$, total darkness). Wild bumble bee colonies were reared from queens collected from State College, Pennsylvania for $B$. impatiens and from Southwest Oregon and Northern California for B. melanopygus and B. vosnesenskii. These colonies were maintained in plastic boxes in the incubator $\left(29^{\circ} \mathrm{C}, 60 \% \mathrm{RH}\right.$, total darkness). All colonies were fed with sugar water containing a preservative (Koppert) and the same source of fresh honey bee-collected pollen (Swarmbustin' Honey, West Grove, PA).

\section{Pupa collection}

Newly formed cocoon clusters were removed from colonies and a small opening was cut in the cocoons to inspect the stage of brood. Only cocoons containing prepupae or spinning last instar larvae were retained for pupal staging and duration analysis. These were placed on a plastic 
161 weigh boat in the incubator $\left(32^{\circ} \mathrm{C}, 60 \% \mathrm{RH}\right.$, total darkness) and were checked every four hours

162 for pupal ecdysis, as prepupae could not be removed from cocoons without problems with 163 ecdysis. Pupae are easily distinguished from the preceding, larva-like pre-pupal stage by their

164 resemblance to the adult shape, which can be seen from the opening of the cocoon (Fig. 1).

165 Newly molted pupae were immediately removed from their cocoons and placed individually in a 166 small $(25 \mathrm{~mm})$ weigh boat (VWR) in the incubator $\left(32^{\circ} \mathrm{C}\right.$ or $29^{\circ} \mathrm{C}$ depending on the experiment, $16760 \% \mathrm{RH}$, total darkness).

168

\section{Pupal staging and photography}

170 Pupae collected by the above described method were examined under the microscope $\left(25^{\circ} \mathrm{C}\right.$,

$17150 \% \mathrm{RH}$ ) every 4-6 hours until adult ecdysis occurred. Morphological observations of different 172 body parts, including the compound eyes (referred to hereafter as CE), face, legs, mesosoma, and 173 metasomal segments, were documented across development to establish stages and their 174 duration. Developmental staging was based on observations of 48 workers and 7 males for $B$. 175 impatiens, collected from 5 Koppert colonies, 3 workers and 20 males for B. vosnesenskii, 176 collected from 2 colonies, and 9 workers and 11 males for B. melanopygus, collected from 5 177 colonies. Defined stages were those that were the least variable and thus most informative for 178 staging within and across species. The duration of each pupal stage was documented for $B$. 179 impatiens workers.

180 Whole pupae as well as specific characteristics used as staging criteria were imaged. 181 High resolution images of whole pupae were taken at each pupal stage using image stacking with 182 a Canon 7D MarkII digital DSLR camera and Zeren Stacker software. Morphological criteria 183 used for staging pupae were imaged with a Nikon Coolpix 4500 digital camera attached to an 184 Olympus SZ61 microscope using an eye piece adaptor (Optem 257014).

185

\section{Examining setal pigmentation during pupal and early adult stages}

To visualize temporal patterns of setal pigmentation during pupal stages, overlying pupal cuticle was removed from metasomal terga in PBS buffer to reveal the developing setae underneath. Images were taken immediately after dissection. Temporal patterns of setal pigmentation posteclosion from the cocoon, otherwise referred to as the callow stage, were visualized for three species - B. impatiens, B. vosnesenskii and B. melanopygus (red form) by imaging, as described 
192 above, whole bees for different time periods post-eclosion $(0,6,12,24$, and 48 hours). To obtain

193 callows, cocoons containing late stage pupae were kept in the incubator and checked every 4

194 hours for adult eclosion. Newly emerged adults were isolated immediately, reared in a plastic

195 box provided with sugar and pollen, and fresh-frozen (color does not change after freezing) at the

196 appropriate stage.

197

198

\section{Measuring temporal patterns of body melanization}

199 The most variable feature across morphological stages of pupal development in bumble bees is

200 pigmentation. To quantify the temporal pattern of pigmentation for each body part, newly molted 201 pupae of $B$. impatiens were reared at $32^{\circ} \mathrm{C}$ and $60 \% \mathrm{RH}$ and imaged every 12 hours until adult 202 ecdysis. Images were transformed to grey scale in Image $\mathrm{J}$ and grey values were measured for 203 different body parts, including the CE, head, mesosoma, legs, antennae and metasoma, for each 204 time point. In grey scale images, the grey value ranges from 0 (white) to 255 (black). To 205 represent the increase of body pigmentation we calculate relative darkness as grey value of area 206 tested/255 X 100\%. One image of a whole pupa was used for each time point. We also estimated 207 overall percent melanic body pigmentation by combining scores across all body parts except for 208 the eye, which involves non-melanin pigmentation.

209

210 Measuring pupal duration

211 Previous studies tended to consider pupation as the period between cocoon formation and

212 eclosion from the cocoon (Cnaani, Robinson \& Hefetz, 2000; Sutcliffe \& Plowright, 1990),

213 which thus includes non-pupal stages of spinning larval and prepupal stages, and newly molted

214 adult bees (Fig. 1). We examine the effects of sex, caste, temperature, and species on total pupal

215 duration through observation of pupa reared under controlled environmental conditions outside

216 the cocoon. We are thus able to demarcate pupal duration more accurately as the time between

217 larva-pupa ecdysis (molting of larval cuticle) and pupa-adult ecdysis (molting of pupal cuticle).

218 To measure pupal duration, newly molted pupae collected as above (accurate within 4 hours)

219 were left undisturbed in the incubator until the last pupal stage. At this stage, we checked the 220 bees every 2-4 hours to document the end of pupation, marked by the pupal cuticle being pushed 221 to the posterior tip of the bee (Jay, 1965). Analysis of the effects of body size, caste, sex, and 222 temperature on developmental duration were performed on B. impatiens, with individuals drawn 
223 from four Koppert ( $\mathrm{n}=83$ individuals) and one wild queen-started colony ( $\mathrm{n}=24$ individuals).

224 Inter-tegular span (ITS), a common measure of bumble bee body size (Cane, 1987; Hagen \&

225 Dupont, 2013), was measured using a microscope eyepiece ruler (Olympus). To avoid potential

226 fluctuations of body size during pupal development, pupal sizes were determined by measuring

227 ITS on newly eclosed adults once the adult ecdysis was complete. Based on the measurement,

228 we designated three size groups for workers and males: small (ITS $<3.5 \mathrm{~mm})$, medium $(3.5 \mathrm{~mm} \leq$

229 ITS $<4.0 \mathrm{~mm}$ ) and large (ITS $\geq 4.0 \mathrm{~mm}$ ). This grouping was chosen to represent the most

230 meaningful by-eye groupings of typical bee sizes (intermediate) as opposed to those that appear

231 atypically large or small. It matches well with size-based task groups in bumble bee workers

232 recognized by Goulson et al. (2002) using B. terrestris, where small workers with inter-tegular

233 span $<3.5$ perform almost exclusively in-nest tasks, large workers with ITS $>4.9$ are mostly

234 foragers, and medium sized workers perform both tasks. Because natural bumble bee colonies

235 maintain a nest temperature between $29^{\circ} \mathrm{C}-32^{\circ} \mathrm{C}$ (Heinrich, 1972; Pomeroy \& Plowright, 1980;

236 Vogt, 1986a), we examined pupal duration for brood reared at $29^{\circ} \mathrm{C}$ and $32^{\circ} \mathrm{C}$ to represent the

237 lowest and highest extremes for brood development. Measurements of pupal duration for $B$.

238 impatiens at these temperatures included small worker $\left(\mathrm{n}=18\right.$ for $32^{\circ} \mathrm{C}, \mathrm{n}=7$ for $\left.29^{\circ} \mathrm{C}\right)$, medium

239 worker $\left(\mathrm{n}=20\right.$ for $32^{\circ} \mathrm{C}, \mathrm{n}=6$ for $\left.29^{\circ} \mathrm{C}\right)$, large worker $\left(\mathrm{n}=15\right.$ for $32^{\circ} \mathrm{C}, \mathrm{n}=6$ for $\left.29^{\circ} \mathrm{C}\right)$, small male

$240\left(\mathrm{n}=7\right.$ for $32^{\circ} \mathrm{C}, \mathrm{n}=3$ for $\left.29^{\circ} \mathrm{C}\right)$, medium male $\left(\mathrm{n}=13\right.$ for $\left.32^{\circ} \mathrm{C}\right)$ and queen $\left(\mathrm{n}=8\right.$ for $32^{\circ} \mathrm{C}, \mathrm{n}=8$ for

$24129^{\circ} \mathrm{C}$ ) treatment groups. A Mann-Whitney test was performed to test temperature effects on

242 pupal duration. To test if there are differences across phenotypes, a One-way ANOVA followed

243 by Tukey's HSD All-Pairwise comparisons were performed for the two temperature treatments

244 separately. To compare between species, we measured pupal duration of small males

245 (ITS $<3.5 \mathrm{~mm}$ ) of B. vosnesenskii (one colony) and B. impatiens at both $32^{\circ} \mathrm{C}$ and $29^{\circ} \mathrm{C}$ (for $B$.

246 vosnesenskii, $\mathrm{n}=8$ for $32^{\circ} \mathrm{C}, \mathrm{n}=3$ for $29^{\circ} \mathrm{C}$ ) and analyzed the data using a Mann-Whitney test.

247

248 RESULTS

249

250 Structures unique to pupae

251 Although mostly simply outlining the adult shape, the bumble bee pupal cuticle exhibits a few

252 characteristics not shared with the adult stage. One obvious feature is the metasomal spicules, a

253 row of small spines near the apical margin of metasomal tergites (Fig. 2A). In B. impatiens, the

254 spicules are present at metasomal segments 2 through 5 (female) or 6 (for male). These spicules 
255 are present throughout pupal development and are shed along with pupal cuticle during pupal256 adult ecdysis without replacement in the adult. These structures are absent in pupae of honey 257 bees (Fig. 2B). Another feature is the presence of inner apical protuberances on the coxae and 258 trochanters of the legs (Fig. 2C\&D). These long protuberances house long setae arising in these 259 segments (Fig. 2E) and appear to act as a brace for the developing legs (Fig. 2C). Honey bee 260 pupae have the same structures at the same location. The coxal and trochanteral protuberances 261 are most distinguishable at the early-mid pupal stage, but collapse and become indistinguishable 262 before pupal-adult ecdysis (Fig. 2 F-H). Similar-shaped structures were also observed on tibial 263 segments, but are retained into adulthood as tibial spines (Michener, 1954).

264

\section{Pupal stages}

266 We describe 20 pupal stages as well as two early post-ecdysis stages that are applicable to all 267 three studied species and across sexes and castes. Key features for each stage are annotated 268 using illustrations or photos (Fig. 3-5). The defined features primarily involve shifts in eye 269 pigmentation in early stages (Fig. 3), followed by shifts in pigmentation of the developing adult 270 cuticle of the main body parts (Fig. 5). Two distinct cuticle pigmentation processes were 271 observed: a "peppering" process, in which the white cuticle acquires a greyish tinge, often 272 starting as fine gray dots before darkening to black, and a "tanning" process, in which cuticle 273 first turns a more even orange-brown color before turning black. Cuticle pigmentation is later 274 followed by pigmentation of the adult setae, which continues until early adult (callow) stages 275 (Fig. 6) Characteristics differing from B. impatiens in other examined species (B. vosnesenskii, 276 B. melanopygus), or by caste or sex, are noted. Simplified morphological criteria for each stage 277 are also provided in Table 1. A photographic guide of whole pupae of each stage featuring $B$. 278 impatiens males is presented in Fig. 7.

279

P0, P1, P2: The white-eyed pupa

281 The white eyed pupa includes three distinct pupal stages, all of which display unpigmented 282 (white) CE and a white body.

283

284 P0: The newly molted pupa (stage P0) has a head and thorax resembling the shape of an adult 285 and an abdomen resembling larvae as it bears 10-11 similarly-sized segments (Fig. 3A). 
286 Abdominal segments 1, 8, 9, and 10 begin to retract, resulting in visible abdominal twitching 287 (Video S1). The first abdominal segment gradually merges with the thorax to form the 288 propodeum. The last three $\left(8^{\text {th }}, 9^{\text {th }}\right.$ and $\left.10^{\text {th }}\right)$ abdominal segments telescope into the preceding 289 segments to form the male and female terminalia. At this stage the female and male are readily 290 separated by the sting and male genitalia at the end of abdomen. This stage is the shortest, lasting $291 \sim 5$ hours.

292

293 P1: This stage begins when retraction of abdominal segments 1, 8, 9, and 10 is completed, and 294 thus abdominal twitching ceases (Video S1, Fig. 3A). This leaves 6 visible female and 7 visible 295 male metasomal segments (Fig. 3A). Leg basitarsi are transparent and cylindrical (Fig. 3B). 296

297 298 299

300

301

302 303 304 305 306 307 308 309 310 311

312 This stage starts with the beginning of the transformation of the ommatidia from dotted to 313 hexagonal. The CE now appears orange. Hexagonal transformation starts at the inner margin of 314 the $\mathrm{CE}$ and ends when all of the eye contains hexagonal shapes except for the outer CE margin 315 (Fig. 3C). 
317 P6: Red-eyed pupa

318 All of the ommatidia are covered with hexagons, including those at the outer margin, resulting in 319 a bright red appearance (Fig. 3C).

320

321

P7/P7L: Maroon to reddish-brown-eyed pupa

322 The CE becomes maroon and progressively darkens to reddish-brown through deepening of the 323 pigment in ommatidial hexagons (Fig. 3C). Being based on eye color, this stage can be difficult 324 to distinguish from P6 at early stages. In B. impatiens, another feature marking the beginning of 325 P7 is the tanning of the border between mesocoxa and mesoepisterum, which appears as two 326 orange lines on each side of the mesothorax in the ventral view (Fig. 3E). This feature is absent 327 in B. vosnesenskii and B. melanopygus. $\mathrm{P} 7$ is one of the longest stages, spanning a period of 328 more than a day. This stage can be divided into two stages (P7, P7L) by distinguishing maroon 329 (P7) from reddish-brown eyes (P7L) (Fig. 7).

330

P8: Dark brown-eyed pupa

332 Eye color becomes dark brown. The beginning of P8 is marked by the initial filling of pigment in 333 the center of each ommatidial hexagon (Fig. 3C). This begins from the center of the CE, and 334 gradually spreads toward the periphery so that by the end of the stage the hexagon patterns are 335 no longer recognizable except for those at the eye margin and the CE is uniformly colored (Fig. 336 3C). The mesosoma now acquires a light pink tinge.

\section{P9: Black-eyed/Red-thorax pupa}

339 P9 is defined by the completion of eye pigmentation, which is now brown-black, and beginning 340 of pigmentation on other body parts. It also marks the end of the first half of the pupal period 341 (50\% of pupation duration). An obvious feature marking the transition to stage P9 is the tanning 342 of a lateral-posterior suture of the mesosoma (Fig. 4). In addition, the red tinge of the mesosoma 343 intensifies, making the color distinct from that of metasoma. Near the end of P9, orange tanning 344 begins in several body parts, including the tarsal claw (Fig. 4), base of mandible, antennal socket, 
345 base of proboscis, wing base, tegula and the suture on the corner of the scutellum. Pepper-

346 colored tanning appears on the pronotum and the margin of the scutellum.

347

348 P10: Peppered-A2 pupa

349 Melanization of the metasoma begins with the apical margin of the first metasomal tergite (Fig.

350 5) as a lightly peppered stripe. In late P10, stripes appear in the lateral-apical margin of each

351 sternite. Orange tanning of the leg now covers tarsomeres and joints.

352

353

354 Melanization spreads to the apical margin of every metasomal tergite, appearing as a narrow

355 black posterior medial stripe on each white tergite separated from peppering on the lateral side.

356 Peppered tanning begins on the frontal line on the head (Fig. 5) and tanning begins in other parts 357 as well including the labrum (orange) (Fig. 5), scape of antennae (greyish) (Fig. 5), female sting 358 (orange), basitarsi and tibiae (orange).

359

360

P12/P12L: Zebra pupa

361 Pepper-colored stripes at the lateral and dorsal apical margins of metasomal tergites are 362 connected to form one continuous stripe circling the entire apical margin (Fig. 5), giving it a 363 zebra-like appearance. The scape turns dark grey (Fig. 5) and the paraocular area and clypeus 364 also turn greyish (Fig. 5). Pigmentation of the black adult setae begins in the late phase of this 365 stage (P12L) (Fig. 5).

366

367

P13/P13L: Appendages blackening pupa

368 Melanization on metasomal tergites progresses anteriorly. Two other traits marking the transition 369 to P13 include: 1) blackening of basal-lateral proboscis, and 2) antennal darkening that has

370 progressed proximally to now include both scape and pedicel (Fig. 5), with flagellomeres

371 acquiring a grey tinge. Melanization on the head continues, with most of the paraocular area and 372 clypeus now black (Fig. 5). At the late phase of P13 (P13L) melanization covers $>1 / 2$ but not all 373 of metasomal tergites and sternites, making the stripe pattern less sharp (Fig. 5). P13L marks the 374 completion of melanization on mesosomal cuticle. 
375

376

377 The cuticle of metasomal tergites and sternites in this stage are black (Fig. 5). Future red or black 378

379

380

381

382

383

384

385

386

387

388

389

390

391

392

393

394

395

396

397

398

399

400

401

402

403

\section{P14: Black-abdomen pupa}

setae begin to melanize, acquiring a greyish-orange tinge, while prospective yellow setae remain white (Fig. 6A). In the case of B. impatiens, setal color on A3-A7 (future black setae) is now distinguished from A2 (future yellow setae) (Fig. 6A). This feature is most obvious in queens and large males and workers. In the head, the $1^{\text {st }}$ and $2^{\text {nd }}$ flagellomeres become black, with remaining flagellomeres becoming dark grey (Fig. 5). The paraocular area and clypeus are completely black (Fig. 5) and the mandible is black in the basal 2/3, with the tip reddish. The labrum blackens in the basal 2/3 with reddish color at the margin (Fig. 5).

\section{P15: Black-bodied pupa}

Melanization of all body parts, including antennae, legs, head and mouthparts finishes, making the non-setal cuticle of the body completely black, with the exception of the distal proboscis and legs which are orange (Fig. 5). The pupal cuticle of the metasoma starts to wrinkle.

\section{P16: Leg-twitching pupa}

Legs start moving freely, perhaps due to the degradation of pupal spines holding the legs in place (Fig. 5). The metasomal segments periscope outwards, making the metasoma appear straighter and longer than previous stages. The pupal cuticle is partially degraded in some parts of the body, especially the legs and metasoma, exposing adult cuticle. Pupal cuticle in the head, such as in the labrum and mandibles starts to wrinkle (Fig. 5). This stage, and pupation, ends with molting of the pupal cuticle.

\section{Quiescent adult}

This stage is marked by the end of adult ecdysis which takes 30 minutes. Adult wings spread but are unmelanized and appear transparent. At this stage, the newly eclosed bee remains in the cocoon largely immobile (Fig. 1D). The pupal cuticle has been removed completely, but sometimes is seen attached to the posterior end of the bee. The setae are matted and not fully 
404 dried. If removed from the cocoon, the bee will lay on its back, moving its legs, unable to stand 405 or walk.

406

407 Callow

408 This stage begins when the bee breaks out from cocoon with wings mostly melanized. Callows

409 actively clean themselves and search for food, often hiding and walking slowly among brood as 410 their cuticle finishes sclerotization. These bees are not aggressive and will not sting. This stage 411 covers the first 1-2 days after eclosion and can be considered complete when the bee is fully 412 melanized and behaving like a normal adult in the nest. We examined callows of three species at 413 different ages (hours after eclosion), and found that the primary morphological changes during 414 callow development is setal pigmentation (Fig. 6B).

415

\section{General pigmentation patterns}

417 A summary plot for timing of melanization on various body parts is provided in Fig. 8 and the 418 relative progression of $\mathrm{CE}$, cuticle (quantified as the sum of values from Fig. 8) and hair color is 419 summarized in Fig. 9. These plots show very little overlap between eye and body pigmentation. 420 Although pigmentation tends to intensify around the same time across non-eye body parts, the 421 order is somewhat staggered (Fig. 8). Pigmentation is complete first in the mesosoma and head, 422 followed by the metasoma, and then the appendages, including antennae and legs, which are not 423 fully pigmented until closer to eclosion. Setae follow similar patterns to the main cuticle, 424 although with a slight delay, with prospective black setae starting pigmentation with a light 425 orange tinge after melanization of metasomal cuticle begins and intensifying gradually as pupae 426 age, towards an orange-grey color that is maintained until around the time of adult ecdysis (Fig. 427 9). At eclosion, prospective black setae are orange-grey, red setae pink-grey, and yellow setae 428 white (Fig. 6B). Color progression of black setae in B. impatiens and B. vosnesenskii and red 429 setae of $B$. melanopygus begins immediately after eclosion, and is complete about 24-48 hours 430 later (Fig. 9). In contrast, pigmentation of yellow setae of all three species examined does not 431 begin until 24 hours after eclosion and completes at about 48-72 hours (Fig. 6B \& 9). 432 433 Pupal duration 
434 Fig. 10A compares pupal duration of different phenotype groups reared at $32^{\circ} \mathrm{C}$ and $29^{\circ} \mathrm{C}$. Mean 435 pupal duration and standard error are provided in Table S1. At $32^{\circ} \mathrm{C}$, pupal duration of workers 436 ranges from 160 hours (6.6 days, small workers $161.9 \pm 1.5 \mathrm{~h})$ to 180 hours (7.5 days, large 437 workers $179 \pm 1.6 \mathrm{~h}$ ), males take an average of 189 hours (7.9 days, small males $188.6 \pm 2.4 \mathrm{~h}$, 438 medium male 189.4 $\pm 1.7 \mathrm{~h})$ and queens about $243.2 \pm 2.2$ hours ( $\sim 10$ days, Fig. 10A; Table S1). 439 Pupal duration is significantly longer at the lower temperature for all groups $\left(29^{\circ} \mathrm{C}\right)(p<0.01$, 440 Mann-Whitney test ) (Fig. 10A, Table S1), with variation among groups in the magnitude of 441 response to temperature. In particular, males and queens respond less than workers. Small, 442 medium and large worker pupae reared at $29^{\circ} \mathrm{C}$ take 20,34 , and 28 hours longer to develop than 443 similarly sized counterparts reared at $32^{\circ} \mathrm{C}$, respectively. However, small males reared at $29^{\circ} \mathrm{C}$ 444 take 15 hours longer, and queen takes 22 hours longer to develop than their $32^{\circ} \mathrm{C}$-reared 445 counterparts (Fig. 10A, Table S1).

446 Overall the ANOVA reveals a strong effect of phenotype (size x caste) on pupal duration $447\left(32^{\circ} \mathrm{C}, F_{5,80}=206.4, p<0.0001 ; 29^{\circ} \mathrm{C}, F_{4,29}=370.12, p<0.0001\right.$, One-Way ANOVA). Body size 448 affects pupal duration in the worker caste significantly, with larger workers taking 18 and 26 449 hours longer to development than small workers at $32^{\circ} \mathrm{C}$ and $29^{\circ} \mathrm{C}$, respectively (Tukey's HSD 450 post-hoc test, with $\alpha=0.05$ ) (Fig. 10A). An effect was not found in males of different size 451 (Tukey's HSD post-hoc test, with $\alpha=0.05$ ). There were also significant differences between 452 castes at both rearing temperatures (Fig. 10A). In general, queens display substantially longer 453 pupal duration than workers (Fig. 10A). For instance, at $32^{\circ} \mathrm{C}$, queen pupae take 81, 71, and 62 454 hours longer to develop than small, medium, and large sized worker pupae, respectively 455 (Tukey's HSD post-hoc test, with $\alpha=0.05$ ). Male pupae also take longer to develop than same456 sized worker counterparts (Fig. 10A) with small sized males taking 27 and 22 hours longer to 457 develop than small sized worker pupae at $32^{\circ} \mathrm{C}$ and $29^{\circ} \mathrm{C}$, respectively (Tukey's HSD post-hoc 458 test, with $\alpha=0.05$ ). The effects of body size within caste also varies between temperatures. 459 Significant differences were found between all three size groups within the worker caste at $32^{\circ} \mathrm{C}$ 460 (Tukey's HSD post-hoc test, with $\alpha=0.05$ ). However, medium-sized workers were no different 461 from large workers at $29^{\circ} \mathrm{C}$ (Tukey's HSD post-hoc test, with $\alpha=0.05$ ). duration of developmental stages for small and medium B. impatiens workers were similar up 
465 until the orange-eyed pupal stage P5 (first 50 hours) (Fig. 9). After this there was an increase in

466 the timing of each stage with increased body size.

467

468

Due to limited availability of bees from $B$. vosnesenskii colonies at the time of

469 experiments, only small males at $32^{\circ} \mathrm{C}$ and $29^{\circ} \mathrm{C}$ were used for comparison (Fig. 10B). B.

470 vosnesenskii male pupae develop 10 hours faster than those of similar size in B. impatiens at 471 $32^{\circ} \mathrm{C}(p=0.0003)$, but no significant difference was found between the two species at $29^{\circ} \mathrm{C}(p$ $472=1.0)$.

473

474 DISCUSSION

475

476

477 The current study provides the first comprehensive description of morphological changes during 478 pupal development in bumble bees. As opposed to previous staging based mostly on eye color, 479 the morphological criteria we established from multiple body parts enables staging of pupal 480 development into smaller, more evenly distributed increments (Fig. 9). This morphological key, 481 annotated with high resolution images, is intended for use in any study on developing bumble 482 bees requiring precise pupal staging.

483

484

The characterization of bumble bee pupal stages presented here differs substantially from those described in honey bees and other bee species, with the exception of eye pigmentation (Elias-Neto, Soares \& Bitondi, 2009). It includes more stages than defined in previous studies on bees, both in eye color and body pigmentation stages (Fig. 9, Table S2). While the relative timing of cuticle melanization to eye pigmentation is largely consistent with observations in honey bees (Rembold, Kremer \& Ulrich, 1980), the progression of melanization differs. This is to be expected given the pronounced difference between the species in their external morphology and pigmentation patterns at adult stages, and their large evolutionary distance ( $>90$ my;

492 Grimaldi \& Engel, 2005). We observed very little difference, however, within and between 493 bumble bee species in pupal traits, consistent with low variability observed within other genera 494 (Fukutomi et al., 2017; Michelette \& Soares, 1993). This key should thus be more broadly 495 applicable across bumble bee species. That said, given that we focused only on a subset of clades 
496 within the bumble bee subgenus Pyrobombus, studies of non-Pyrobombus taxa may want to use

497 this as a guideline for developing a more taxon-specific staging.

498

499

500

Our study highlights several features of pupal development in bumble bees. We first note the features unique to the pupal cuticle that differ from the pharate adult, notably apical tergal

501 spicules and leg protuberances. Large across-species variation has been found in the pupal

502 spicules in bees in terms of their number, size, positions and shapes (Baker, Kuhn \& Bambara,

503 1985; Cardale, 1968; Michener, 1954; Rozen \& Jerome, 1990; 2000; Torchio \& Trostle, 1986).

504 We noted them to be pronounced in bumble bees but absent in honey bees. Although the

505 function of these is unclear, given their morphology they may serve a purpose as

506 mechanosensory setae or for anchoring while in the pupal cocoon, and thus may differ depending

507 on the nature of their pupal environment. Pupal leg protuberances, also variably called spines

508 (Michener, 1954) or tubercles (Rozen \& Jerome, 1990), may be relevant to setal development

509 (Michener, 1954) given that they are filled with long setae, but appear to embrace the leg, thus

510 may be holding the legs in place during development. We also observed the shift in pupal

511 segments around the larval-pupal transition. Most non-sawfly Hymenoptera exhibit the

512 synapomorphy of a constriction between their abdominal tergites 1 and 2 that leads to the

513 flexible wasp waist separating the mesosoma from the metasoma. We provide a video (Video

514 S1) observing the regression in these segments that recapitulates the progression of events

515 involved in the formation of the wasp waist.

516

517

We have made several observations regarding the shifts in pigmentation across pupal

518 development. We note that the eye follows a dot-to-hexagonal progression likely reflecting

519 development of ommatidia that aligns with shifts in intensification of eye color (Fig. 3C). Eye

520 color also appears to be decoupled from cuticle color, with the cuticle not pigmenting until eye

521 color is complete. Eye color comes from ommochromes used as filtering pigments in the

522 developing ommatidia, a different class of pigments from the brown-black cuticular pigments,

523 which are melanin. Melanization was observed to start in body sutures, including legs joints and

524 sutures on the mesosoma, and then tended to fill in first in the mesosoma, then the metasoma,

525 followed by a progression of darkening from proximal to distal on the appendages. In the

526 metasoma we observed striping patterns in these bees as cuticle melanizes that move posterior to 
527 anterior on metasomal tergites (Fig. 5). It is interesting to consider why melanin progresses as it

528 does, with possibilities being related to sources of melanin precursors like tyrosine derived from 529 the center of the body or the availability of oxygen required for melanization (Lerner \&

530 Fitzpatrick, 1950). Two melanization processes were observed to take place on the primary

531 cuticle, some of which involve gray to black and others which start with a more ochre color, in

532 line with alternative routes to black color in these bees noted by Milliron (1971). This could

533 involve differences in melanin pathways, including differences between pheomelanin and

534 eumelanin or other quinone derivatives (Hines et al., 2017). Finally, the yellow setal

535 pigmentation is also fairly decoupled from melanin pigmentation, occurring a day or so after

536 adult eclosion when melanization is mostly complete. This decoupling likely occurs because

537 yellow setae are colored by a different type of pigment, likely a pterin (Hines, 2008).

538

539

540 Pupal duration

541 We observed shorter pupal duration in all size/caste groups when they were reared at higher

542 temperatures. Both temperatures used are within the typical range of temperatures observed in

543 the brood of bumble bee colonies (Heinrich, 1972; Pomeroy \& Plowright, 1980; Seeley, 1981;

544 Vogt, 1986a). Higher temperatures within a colony than outside are achieved by the activity of

545 the adults and active thermoregulation of the brood through incubation (Heinrich, 1972; Seeley,

546 1981). This suggests that colony development will be impacted by incubation efforts. The

547 negative correlation between rearing temperature and pupal duration is consistent with results

548 from other insects (Elmes \& Wardlaw, 1983; Foley, 1981; Kipyatkov, Lopatina \& Imamgaliev,

549 2005; Penick et al., 2017). Interestingly, the worker caste is affected more than males and queens

550 by temperature, with greatest effect on medium-sized workers, suggesting that developmentally

551 plastic phenotypes like size and caste may have differential response thresholds to environmental

552 conditions.

553

554

Our study reveals a positive correlation between body size and pupal duration within

555 workers, with larger workers taking longer to develop than smaller ones. This could explain variation in worker pupal duration (up to 5 days) in previous studies (Katayama, 1973; Sakagami, Akahira \& Zucchi, 1967). Given that pupal and adult size is determined at the onset 
558 of pupation from larval size, pupal duration is likely a consequence of body size rather than vice

559 versa. In our observations, the timing of eye pigmentation phases did not differ by bee size but

560 later stages involved in melanic pigmentation across the body did (Fig. 9). This may be because

561 the eye is smaller and involves a single-layer (thus reduced complexity) (Cagan \& Ready, 1989),

562 while melanization would need to take place over a larger surface and may be impacted by

563 signals coming from other parts of the body, which may take longer in larger individuals. The

564 differences we find in both duration and potential lengths of specific stages by body size, means

565 standardization of pupal stages (e.g., for genetic research) is best done on similarly sized

566 individuals.

567

568

569

A positive correlation between body size and duration can fail when sexes and castes are considered. In Drosophila, male pupae are smaller than females but take longer to eclose

570 (Nilssen, 2006; Nunney, 2007), and in the honey bee Apis mellifera, queen pupae, which are

571 larger than worker pupae, have a shorter pupal duration (Rembold, Kremer \& Ulrich, 1980).

572 Bumble bee queens do not follow the same patterns as honey bees, as queens have much longer

573 pupal duration than workers and males. This matches expectations from body size, as queens are

574 much larger than workers. The rationale for why a honey bee queen would take less time is

575 interesting to consider. It could be due to their caste being determined more by diet quality

576 (Kamakura, 2011). Alternatively, the contrast between bumble bees and honey bees may be

577 explained by their life history: honey bee queens are under strong selection to develop quickly as

578 the first queen to emerge typically becomes the new queen and kills the remaining queen-

579 destined brood (Degrandi-Hoffman et al., 1998; Michener, 1974), a practice not exhibited by

580 bumble bees which disperse and independently start their own nest. Bumble bee males, however,

581 exhibited longer pupal duration than workers regardless of their body size, and the duration of

582 their development was less sensitive to relative body size. Longer pupal duration in males may

583 be because gonotrophic development is more complicated in males than females, thus requiring

584 more time to complete metamorphosis (Breev, Zagretdinov \& Minar, 1980). Different sexes and

585 castes must therefore have adaptations driving duration that are independent of the effects of 586 size.

$587 \quad$ We also found a difference between B. impatiens and B. vosnesenskii in pupal duration.

588 Differences within and between closely-related species in developmental timing are not 
589 uncommon in insects (Elmes \& Wardlaw, 1983; Fukutomi et al., 2017; Ma, Huang \& Wang, 590 2015; Nilssen, 2006; Sgolastra et al., 2012), and, in bumble bees, differences in habitat have 591 been suggested to select for different developmental rates (Sakagami, Akahira \& Zucchi, 1967).

592 These two species differ in their climatic niche, as B. vosnesenkii is a Pacific coastal bumble bee 593 and has a longer season with milder and wetter weather than B. impatiens, which is exposed to 594 eastern North American cool temperate, moderately wet seasonality. This could also explain 595 observed differences in plasticity in these species, as the response to temperature in

596 developmental duration was greater in B. vosnesenskii than in B. impatiens.

597

598

\section{CONCLUSIONS}

599

600

This study provides detailed morphological pupal staging criteria, insights into pupal duration

601 under various conditions, and characterization of temporal patterns of pigmentation in bumble 602 bees, all of which should help seed future studies on genetic and physiological mechanisms

603 regulating adult phenotypes in these developmentally highly plastic and phenotypically diverse

604 bees. Our staging system is established based completely on external morphology of the pupa. It

605

606

607

608

609

610

611

612

613

\section{REFERENCES}

615

616

617

618

619

620

621

remains to be studied how these features are generated from internal mechanisms and how these stages correspond to critical physiological aspects of the bee, such as hormone titers, ovarian and brain development, that translate to important aspects of phenotypic plasticity in these bees.

\section{ACKNOWLEDGEMENTS}

The authors wish to thank Daniel Snelling, Sarthok Rahman, Elyse McCormick, Istvan Miko and Colin Wright for their constructive comments that helped to improve the manuscript.

Amsalem E, Galbraith DA, Cnaani J, Teal PE, and Grozinger CM. 2015. Conservation and modification of genetic and physiological toolkits underpinning diapause in bumble bee queens. Molecular ecology 24:5596-5615 DOI: 10.1111/mec.13410 Baker J, Kuhn E, and Bambara S. 1985. Nests and immature stages of leafcutter bees (Hymenoptera: Megachilidae). Journal of the Kansas Entomological Society 58:290-313

Bellés X. 2010. Beyond Drosophila: RNAi In vivo and functional genomics in insects. Annual review of entomology 55:111-128 DOI: 10.1146/annurev-ento-112408-085301. 
622 Berry DL, and Baehrecke EH. 2007. Growth arrest and autophagy are required for salivary

623 gland cell degradation in Drosophila. Cell 131:1137-1148 DOI: 10.1016/j.cell.2007.10.048.

624 Bortolotti L, Duchateau MJ, and Sbrenna G. 2001. Effect of juvenile hormone on caste

625 determination and colony processes in the bumble bee Bombus terrestris. Entomologia

626 Experimentalis et Applicata 101:143-158 DOI: 10.1046/j.1570-7458.2001.00899.x

627 Breev K, Zagretdinov R, and Minar J. 1980. Influence of constant and variable temperatures

628 on pupal development of the sheep bot fly (Oestrus ovis L.). Folia parasitologica 27:359-365

629 Brutscher LM, and Flenniken ML. 2015. RNAi and antiviral defense in the honey bee.

630 Journal of Immunology Research 2015:1-10 DOI: 10.1155/2015/941897.

631 Cagan RL, and Ready DF. 1989. The emergence of order in the Drosophila pupal retina.

632 Developmental Biology 136:346-362 DOI: 10.1016/0012-1606(89)90261-3.

633 Cane JH. 1987. Estimation of bee size using intertegular span (Apoidea). Journal of the Kansas 634 Entomological Society 60:145-147

635 Cardale J. 1968. Immature stages of Australian Anthophorinae (Hymenoptera: Apoidea).

636 Australian Journal of Entomology 7:35-41

637 Cardoso-Júnior CAM, Silva RP, Borges NA, de Carvalho WJ, Walter SL, Simões ZLP,

638 Bitondi MMG, Ueira Vieira C, Bonetti AM, and Hartfelder K. 2017. Methyl farnesoate

639 epoxidase ( $\mathrm{mfe}$ ) gene expression and juvenile hormone titers in the life cycle of a highly eusocial

640 stingless bee, Melipona scutellaris. Journal of Insect Physiology 101:185-194 DOI:

641 10.1016/j.jinsphys.2017.08.001.

642 Cartar RV, and Dill LM. 1991. Costs of energy shortfall for bumble bee colonies: Predation,

643 social parasitism, and brood development. The Canadian Entomologist 123:283-293 DOI:

644 10.4039/Ent123283-2.

645 Chen X, Hu Y, Zheng H, Cao L, Niu D, Yu D, Sun Y, Hu S, and Hu F. 2012. Transcriptome

646 comparison between honey bee queen- and worker-destined larvae. Insect Biochemistry and

647 Molecular Biology 42:665-673 DOI: 10.1016/j.ibmb.2012.05.004.

648 Cnaani J, Borst DW, Huang Z-Y, Robinson GE, and Hefetz A. 1997. Caste determination in 649 Bombus terrestris: differences in development and rates of $\mathrm{JH}$ biosynthesis between queen and 650 worker larvae. Journal of Insect Physiology 43:373-381 DOI: 10.1016/S0022-1910(96)00106-0.

651 Cnaani J, Robinson GE, and Hefetz A. 2000. The critical period for caste determination in

652 Bombus terrestris and its juvenile hormone correlates. Journal of Comparative Physiology A

653 186:1089-1094 DOI: 10.1007/s003590000.

654 Cnaani J, Schmid-Hempel R, and Schmidt JO. 2002. Colony development, larval 655 development and worker reproduction in Bombus impatiens Cresson. Insectes Sociaux 49:164-

656170 DOI: 10.1007/s00040-002-8297-8.

657 Collins DH, Mohorianu I, Beckers M, Moulton V, Dalmay T, and Bourke AF. 2017.

658 MicroRNAs associated with caste determination and differentiation in a primitively eusocial 659 insect. Scientific Reports 7:45674 DOI: 10.1038/srep45674. 
660 Couvillon MJ, and Dornhaus A. 2009. Location, location, location: larvae position inside the 661 nest is correlated with adult body size in worker bumble-bees (Bombus impatiens). Proceedings 662 of the Royal Society B: Biological Sciences 276:2411-2418 DOI: 10.1098/rspb.2009.0172.

663 Couvillon MJ, Jandt JM, Duong N, and Dornhaus A. 2010. Ontogeny of worker body size 664 distribution in bumble bee (Bombus impatiens) colonies. Ecological Entomology 35:424-435 665 DOI: 10.1111/j.1365-2311.2010.01198.x.

666 Cridge AG, Lovegrove MR, Skelly JG, Taylor SE, Petersen GEL, Cameron RC, and 667 Dearden PK. 2017. The honeybee as a model insect for developmental genetics. genesis 55:1-12 668 DOI: $10.1002 / \mathrm{dvg} .23019$.

669 Cruz-Landim CD, and Mello MLS. 1967. The post-embryonic changes in Melipona 670 quadrifasciata anthidioides lep.(hym. apoidea) II. Development of the salivary glands system. 671 Journal of Morphology 123:481-502 DOI: 10.1002/jmor.1051230410.

672 Daly HV. 1966. Biological studies on Ceratina dallatorreana, an alien bee in California which 673 reproduces by parthenogenesis (Hymenoptera: Apoidea). Annals of the Entomological Society of 674 America 59:1138-1154 DOI: 10.1093/aesa/59.6.1138.

675 Dean C-AE. 2016. Developmental timing of pupation and analysis of color pattern response to 676 thermal stress in Bombus impatiens (Hymenoptera: Apidae) D. Phil. Thesis. University of 677 Illinois at Urbana-Champaign.

678 Degrandi-Hoffman G, Watkins JC, Collins AM, Loper GM, Martin JH, Arias MC, and 679 Sheppard WS. 1998. Queen developmental time as a factor in the africanization of European 680 Honey bee (Hymenoptera: Apidae) populations. Annals of the Entomological Society of America 681 91:52-58 DOI: 10.1093/aesa/91.1.52.

682 Dong J, Han L, Wang Y, Huang J, and Wu J. 2017. Transcript expression bias of 683 phosphatidylethanolamine binding protein gene in bumble bee, Bombus lantschouensis 684 (Hymenoptera: Apidae). Gene 627:290-297 DOI: 10.1016/j.gene.2017.06.041.

685 Elias-Neto M, Soares M, P.M., and Bitondi M, M.G. 2009. Changes in integument structure 686 during the imaginal molt of the honey bee. Apidologie 40:29-39 DOI: 10.1051/apido:2008064.

687 Elmes GW, and Wardlaw JC. 1983. A comparison of the effect of temperature on the 688 development of large hibernated larvae of four species of Myrmica (Hym. Formicidae). Insectes 689 Sociaux 30:106-118 DOI: 10.1007/bf02225661.

690 Foley DH. 1981. Pupal development rate of Heliothis armiger (Hubner) (lepidoptera: Noctuidae) 691 under constant and alternating temperatures. Australian Journal of Entomology 20:13-20 DOI:

692 10.1111/j.1440-6055.1981.tb00993.x.

693 Fukutomi Y, Matsumoto K, Agata K, Funayama N, and Koshikawa S. 2017. Pupal 694 development and pigmentation process of a polka-dotted fruit fly, Drosophila guttifera (Insecta, 695 Diptera). Development Genes and Evolution 227:171-180 DOI: 10.1007/s00427-017-0578-3.

696 Gillott, C. 1991. Entomology. New York: Plenum Press.

697 Goulson D, Peat J, Stout JC, Tucker J, Darvill B, Derwent LC, and Hughes WOH. 2002.

698 Can alloethism in workers of the bumble bee, Bombus terrestris, be explained in terms of

699 foraging efficiency? Animal Behaviour 64:123-130 DOI: 10.1006/anbe.2002.3041. 
700 Grimaldi D, and Engel MS. 2005. Evolution of the Insects. New York: Cambridge University 701 Press.

702 Groh C, Tautz J, and Rössler W. 2004. Synaptic organization in the adult honey bee brain is 703 influenced by brood-temperature control during pupal development. Proceedings of the National 704 Academy of Sciences 101:4268-4273 DOI: 10.1073/pnas.0400773101.

705 Gu L, and Knipple DC. 2013. Recent advances in RNA interference research in insects:

706 Implications for future insect pest management strategies. Crop Protection 45:36-40 DOI:

707 10.1016/j.cropro.2012.10.004.

708

709

710

711

712

713

714

715

716

717

718

719

720

721

722

723

724

725

726

727

728

729

730

731

732

733

734

735

736

737

738

739

740

Hagen M, and Dupont YL. 2013. Inter-tegular span and head width as estimators of fresh and dry body mass in bumble bees (Bombus spp.). Insectes Sociaux 60:251-257 DOI: 10.1007/s00040-013-0290-x.

Hartfelder K, and Rembold H. 1991. Caste-specific modulation of juvenile hormone III content and ecdysteroid titer in postembryonic development of the stingless bee, Scaptotrigona postica depilis. Journal of Comparative Physiology B 160:617-620 DOI: 10.1007/bf00571258.

Heinrich B. 1972. Physiology of brood incubation in the bumble bee queen, Bombus vosnesenskii. Nature 239:223 DOI: 10.1038/239223a0.

Hines HM. 2008. Bumble bees (Apidae: Bombus) through the ages: Historical biogeography and the evolution of color diversity D. Phil. Thesis. University of Illinois at Urbana-Champaign.Hu Z, Lee KS, Choo YM, Yoon HJ, Lee SM, Lee JH, Kim DH, Sohn HD, and Jin BR. 2010. Molecular cloning and characterization of 1-Cys and 2-Cys peroxiredoxins from the bumble bees Bombus ignitus. Comparative Biochemistry and Physiology Part B: Biochemistry and Molecular Biology 155:272-280 DOI: 10.1016/j.cbpb.2009.11.011.

Jay SC. 1965. Laboratory rearing studies of the postcapping stages of the honey bee (Apis mellifera L.): I. Rearing brood outside cells. Canadian Journal of Zoology 43:541-552 DOI: 10.1139/z65-053.

Jones BM, Wcislo WT, and Robinson GE. 2015. Developmental transcriptome for a facultatively eusocial bee, Megalopta genalis. G3: Genes|Genomes|Genetics 5:2127-2135 DOI: $10.1534 / \mathrm{g} 3.115 .021261$.

Kamakura M. 2011. Royalactin induces queen differentiation in honeybees. Nature 473:478 DOI: $10.1038 /$ nature10093.

Katayama E. 1973. Observations on the brood development in Bombus ignitus (Hymenoptera, apidae) : II. Brood development and feeding habits. Kontyu 41:203-216

Kipyatkov V, Lopatina E, and Imamgaliev A. 2005. Duration and thermal reaction norms of development are significantly different in winter and summer brood pupae of the ants Myrmica rubra Linnaeus, 1758 and M. ruginodis Nylander, 1846 (Hymenoptera, Formicidae). Myrmecologische Nachrichten 7:69-76

Lerner AB, and Fitzpatrick TB. 1950. Biochemistry of melanin formation. Physiological reviews 30:91-126 DOI: 10.1152/physrev.1950.30.1.91.

Li B, Hou L, Zhu D, Xu X, An S, and Wang X. 2018. Identification and caste-dependent expression patterns of DNA methylation associated genes in Bombus terrestris. Scientific Reports 8:2332 DOI: 10.1038/s41598-018-20831-1. 
741 Li J, Huang J, Cai W, Zhao Z, Peng W, and Wu J. 2010. The vitellogenin of the bumble bee, 742 Bombus hypocrita: studies on structural analysis of the cDNA and expression of the mRNA.

743 Journal of Comparative Physiology B 180:161-170 DOI: 10.1007/s00360-009-0434-5.

744 Ma T, Huang J, and Wang J-F. 2015. Study on the pupal morphogenesis of Chrysomya 745 rufifacies (Macquart) (Diptera: Calliphoridae) for postmortem interval estimation. Forensic 746 Science International 253:88-93 DOI: 10.1016/j.forsciint.2015.06.005.

747 Mänd M, Kuusik A, Martin A-J, Williams IH, Luik A, Karise R, Metspalu L, and Hiiesaar 748 K. 2005. Discontinuous gas exchange cycles and active ventilation in pupae of the bumble bee

749 Bombus terrestris. Apidologie 36:561-570 DOI: 10.1051/apido:2005045.

750 Medved V, Huang ZY, and Popadić A. 2014. Ubx promotes corbicular development in Apis 751 mellifera. Biology Letters 10:20131021 DOI: 10.1098/rsbl.2013.1021.

752 Michelette EF, and Soares AE. 1993. Characterization of preimaginal developmental stages in 753 Africanized honey bee workers (Apis mellifera L). Apidologie 24:431-440 DOI:

754 10.1051/apido:19930410.

755 Michener CD. 1954. Observations on the pupae of bees. Pan-Pacific Entomologist 30:63-70

756 Michener CD. 1974. The social behavior of the bees: a comparative study. Cambridge: Harvard 757 University Press.

758 Michener CD. 2000. The bees of the world. Baltimore: Johns Hopkins University Press.

759 Milliron HE. 1971. A monograph of the Western Hemisphere bumble bees (Hymenoptera:

760 Apidae; Bombinae). I. The Memoirs of the Entomological Society of Canada 103:1-80

761 Nilssen A. 2006. Pupal biology and metamorphosis behaviour. In: Colwell DD, Martin JR Hall, 762 and Philip J. Scholl, ed. The oestrid flies: biology, host-parasite relationships, impact and 763 management. Cambridge: CABI, 124-139.

764 Nunney L. 2007. Pupal period and adult size in Drosophila melanogaster: a cautionary tale of 765 contrasting correlations between two sexually dimorphic traits. Journal of Evolutionary Biology 766 20:141-151 DOI: 10.1111/j.1420-9101.2006.01214.x.

767 Penick CA, Diamond SE, Sanders NJ, and Dunn RR. 2017. Beyond thermal limits:

768 comprehensive metrics of performance identify key axes of thermal adaptation in ants.

769 Functional Ecology 31:1091-1100 DOI: 10.1111/1365-2435.12818

770 Pereboom JJM, Jordan WC, Sumner S, Hammond RL, and Bourke AFG. 2005. Differential 771 gene expression in queen-worker caste determination in bumble bees. Proceedings of the Royal 772 Society B: Biological Sciences 272:1145-1152 DOI: 10.1098/rspb.2005.3060.

773 Plowright RC, and Jay SC. 1968. Caste differentiation in bumble bees (Bombus Latr.: Hym.) I. 774 — The determination of female size. Insectes Sociaux 15:171-192 DOI: 10.1007/bf02223465.

775 Pomeroy N, and Plowright RC. 1980. Maintenance of bumble bee colonies in observation 776 hives (Hymenoptera: Apidae). The Canadian Entomologist 112:321-326 DOI:

777 10.4039/Ent112321-3.

778 Price J, Harrison MC, Hammond RL, Adams S, Gutierrez-Marcos JF, and Mallon EB. 779 2018. Alternative splicing associated with phenotypic plasticity in the bumble bee Bombus 780 terrestris. Molecular ecology 27:1036-1043 DOI: 10.1111/mec.14495. 
781 Rapti Z, Duennes MA, and Cameron SA. 2014. Defining the colour pattern phenotype in 782 bumble bees (Bombus): a new model for evo devo. Biological Journal of the Linnean Society 783 113:384-404 DOI: 10.1111/bij.12356.

784 Rembold H, Kremer J-P, and Ulrich GM. 1980. Characterization of postembryonic

785 developmental stages of the female castes of the honey bee, Apis mellifera L. Apidologie 11:29-

78638 DOI: 10.1051/apido:19800104.

787 Ribeiro MF. 1994. Growth in bumble bee larvae: relation between development time, mass, and 788 amount of pollen ingested. Canadian Journal of Zoology 72:1978-1985 DOI: 10.1139/z94-270.

789 Rozen J, and Jerome G. 1990. Pupa of the bee Pararhophites orobinus (Hymenoptera:

790 Apoidea: Megachilidae). Journal of the New York Entomological Society 98:379-382

791

792

793

794

795

796

797

798

799

800

801

802

803

804

805

806

807

808

809

810

811

812

813

814

815

816

817

818

Rozen J, and Jerome G. 2000. Pupal descriptions of some cleptoparasitic bees (Apidae), with a preliminary generic key to pupae of cleptoparasitic bees (Apoidea). American Museum Novitates 3289:1-19 DOI: 10.1206/0003-0082(2000)289<0001:PDOSCB>2.0.CO;2.

Sakagami SF, Akahira Y, and Zucchi R. 1967. Nest architecture and brood development in a neotropical bumble bee, Bombus atratus. Insectes Sociaux 14:389-413

Seeley T. 1981. Regulation of temperature in the nests of social insects. In: Heinrich B, ed. Insect thermoregulation. New York: Wiley,159-234.

Sgolastra F, Kemp WP, Maini S, and Bosch J. 2012. Duration of prepupal summer dormancy regulates synchronization of adult diapause with winter temperatures in bees of the genus Osmia. Journal of Insect Physiology 58:924-933 DOI: 10.1016/j.jinsphys.2012.04.008.

Stern DL. 1998. A role of Ultrabithorax in morphological differences between Drosophila species. Nature 396:463 DOI: 10.1038/24863.

Sutcliffe GH, and Plowright RC. 1990. The effects of pollen availability on development time in the bumble bee Bombus terricola K. (Hymenoptera: Apidae). Canadian Journal of Zoology 68:1120-1123 DOI: $10.1139 / \mathrm{z} 90-166$.

Tasei J-N, and Aupinel P. 2008. Nutritive value of 15 single pollens and pollen mixes tested on larvae produced by bumble bee workers (Bombus terrestris, Hymenoptera: Apidae). Apidologie 39:397-409 DOI: 10.1051/apido:2008017.

Tautz J, Maier S, Groh C, Rössler W, and Brockmann A. 2003. Behavioral performance in adult honey bees is influenced by the temperature experienced during their pupal development. Proceedings of the National Academy of Sciences 100:7343-7347 DOI: 10.1073/pnas.1232346100.

Thorp RW. 1969. Ecology and behavior of Anthophora edwardsii (Hymenoptera: Anthophoridae). The American Midland Naturalist 82:321-337 DOI: 10.2307/2423781.

Torchio PF, and Trostle GE. 1986. Biological Notes on Anthophora urbana urbana and Its Parasite, Xeromelecta californica (Hymenoptera: Anthophoridae), including Descriptions of Late Embryogenesis and Hatching. Annals of the Entomological Society of America 79:434-447 DOI: 10.1093/aesa/79.3.434. 
819 Vogt FD. 1986a. Thermoregulation in bumble bee colonies. I. Thermoregulatory versus brood820 maintenance behaviors during acute changes in ambient temperature. Physiological Zoology

$821 \quad 59: 55-59$

822 Vogt FD. 1986b. Thermoregulation in bumble bee colonies. II. Behavioral and demographic

823 variation throughout the colony cycle. Physiological Zoology 59:60-68

824 White KP, Rifkin SA, Hurban P, and Hogness DS. 1999. Microarray analysis of Drosophila 825 development during metamorphosis. Science 286:2179-2184 DOI:

826 10.1126/science.286.5447.2179.

827

828 


\section{Table 1 (on next page)}

Generalized staging criteria for pupal development of $B$. impatiens.

$*=$ B. impatiens only 


\begin{tabular}{l|l|l}
\hline \hline \multirow{2}{*}{ Stage } & \multicolumn{2}{|c}{ Staging Criteria } \\
\cline { 2 - 3 } & \multicolumn{1}{|c}{ Primary } & \multicolumn{1}{c}{ Secondary } \\
\hline P-0 & White eyed, >7 metasomal segments & First abdominal segment not retracted \\
P-1 & White eyed, 6 or 7 metasomal segments & Leg segment cylindrical and transparent \\
P-2 & White-eyed, Leg segments flat and opaque & \\
P-3 & Yellow-eyed & Tanned suture on tegula/forewing junction* \\
P-4 & Peach-eyed & Dotted ommatidia \\
P-5 & Orange-eyed & Both hexagonal and dotted ommatidia \\
P-6 & Red-eyed & Hexagonal ommatidia \\
P-7/7L & Maroon-Brown-eyed & Tanned meso-coxa/mesepisternum suture* \\
P-8 & Brown-eyed & Hexagons at eye center filled \\
P-9 & Red tinge on mesosoma & Tanned suture on corner of scutellum \\
P-10 & Black medial strip on A2 & Peppering at frontal line \\
P-11 & Broken apical metasomal stripes & Grey antennal scape \\
P12/12L & Complete apical metasomal stripes & Black setae star to turn orange \\
& & \\
P-13/13L & Blackening of lateral-basal proboscis & Black antennal scape, tergites greyish-orange \\
P-14 & Abdomen fully black & Flagellomere greyish orange \\
P-15 & Antennae fully black & Whole body black \\
P-16 & Leg twitching & Extended and wrinkled metasoma \\
\hline Table 1: Genalized staging criteria for pupal development of $\boldsymbol{B}$ impatiens.
\end{tabular}

\section{Table 1: Generalized staging criteria for pupal development of $\boldsymbol{B}$. impatiens.}

$2 *=$ B. impatiens only

3

4

5

6 
Figure 1

Cocoons of $B$. impatiens at different stages.

Stages include a prepupa (A), pupa (B \& C) and a newly eclosed adult bee (D). 


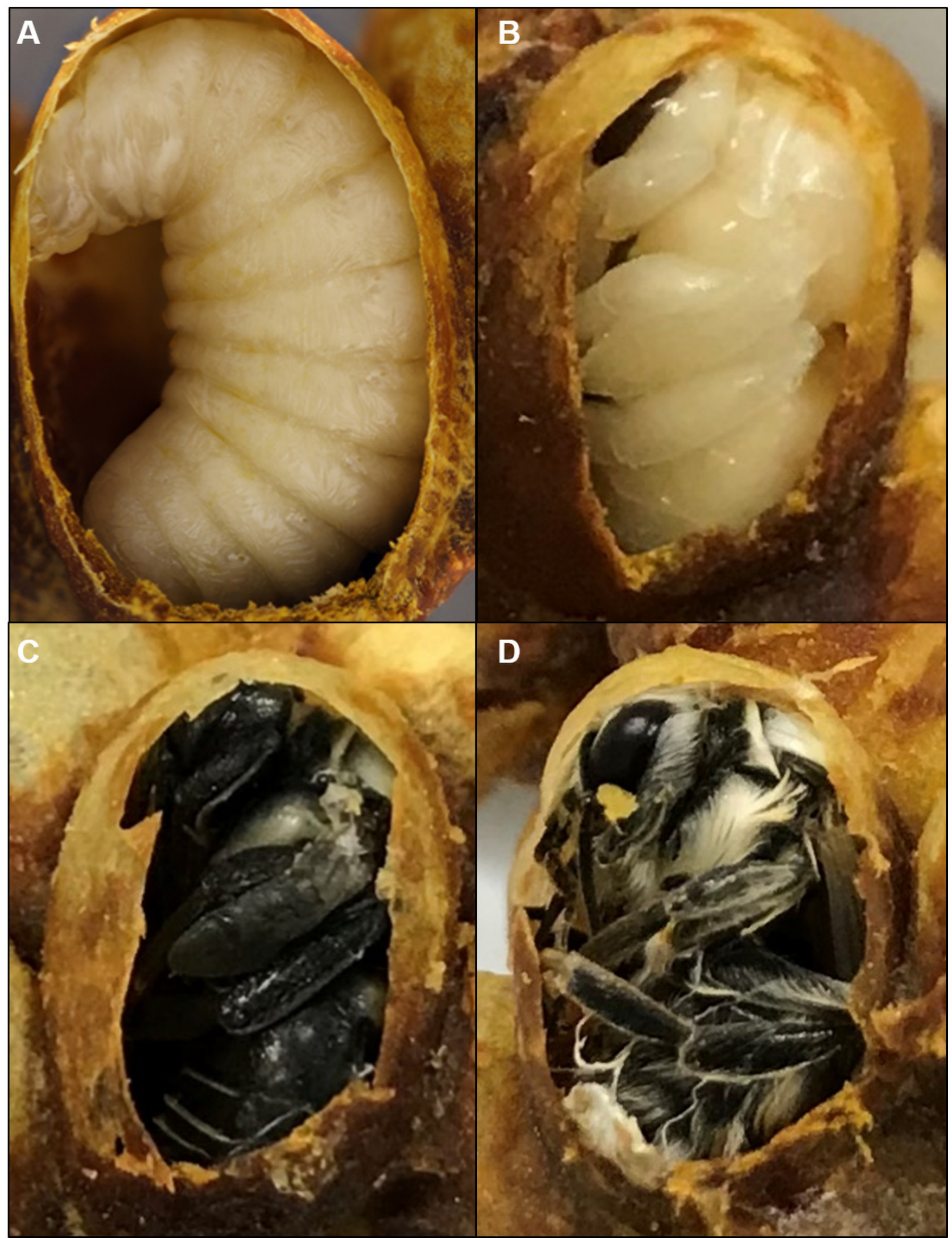




\section{Figure 2}

\section{Characteristics unique to pupal stages.}

Metasomal tergal spicules are present in bumble bee pupae (A), but absent in honey bee pupae (B). C. The trochanteral protuberance (Trp) braces the basitarus (Btar) of the foreleg (Flg) and midleg (Mlg), suggesting a function as a leg hook that maintains proper folding of pupal legs. The tibial spine (Tbsp) of the hind leg is also shown. D. A schematic illustration of the bumble bee pupal leg showing coxal (Cxp) and trochanteral (Trp) protuberances and tibial (Tbsp) spines. Black lines, pupal cuticle; grey lines, developing adult cuticle; grey shades, developing setae. Illustration is modified from Michener, 1954. E. Trochanteral protuberance with developing adult hair bundle (broken line) encased in pupal cuticle. F-H, Coxal and trochanteral protuberances of mid and hind legs of early, mid, and late-stage pupae, respectively. The tibia and basitarsus are removed to reveal the protuberances. Note the degeneration of these protuberances in the late pupa (H). Mst, Metasomal tergite; Mtsp, Metasomal tergal spicules; Cx, coxa; Tr, trochanter; Fm, Femur; Tb, tibia; Btar; basitarsus. Scale bar unit: $\mathrm{mm}$ 


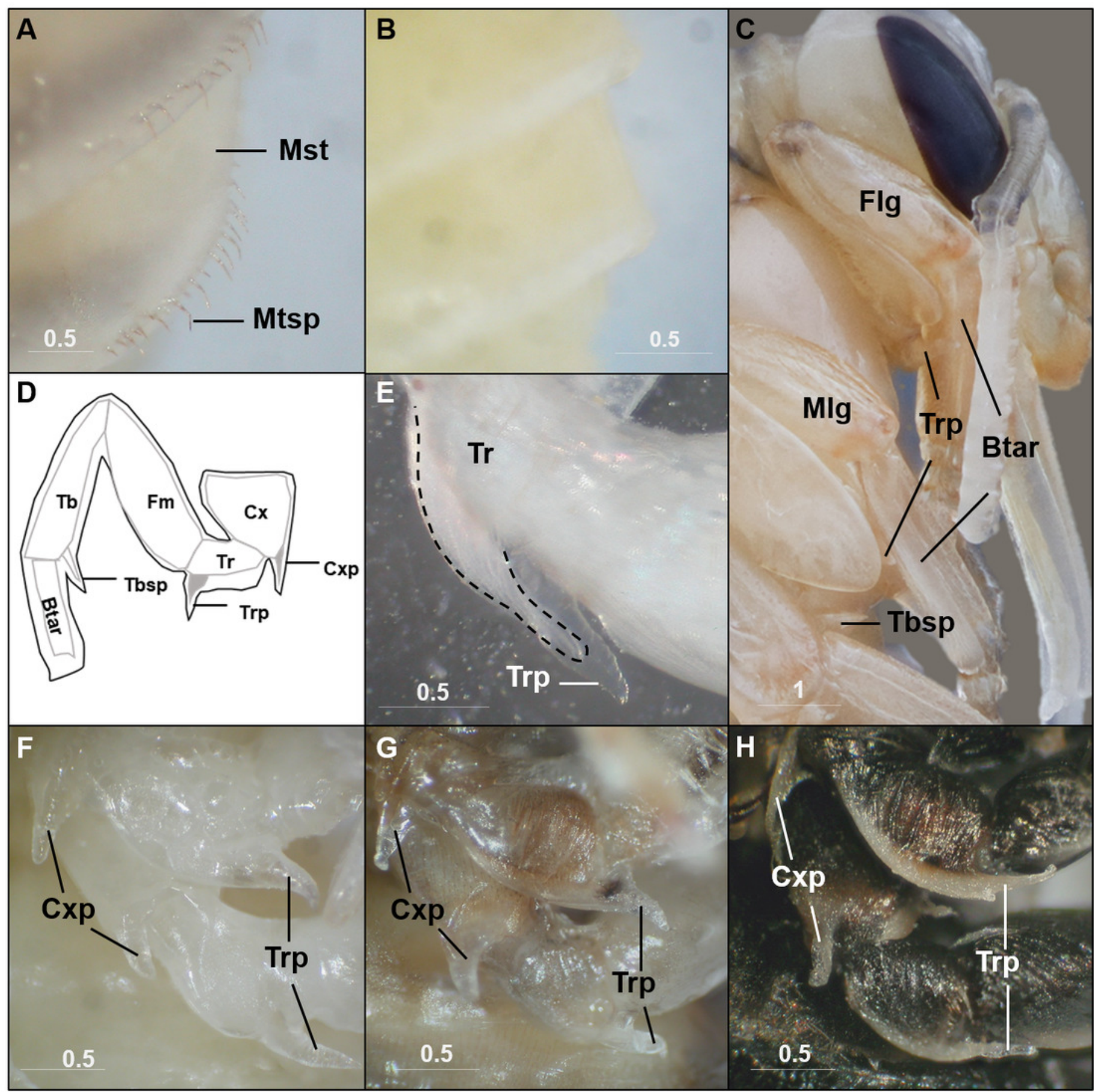




\section{Figure 3}

Morphological criteria marking transitions to P0-P8.

A\&B: Illustration and photo for transition from P0 to P1. Note the retraction of A1 and A8-10.

$C \& D$ : Illustration and photo for changes in shapes of basitarsi of the hind leg (broken lines) of B. impatiens workers in the transition from P1 to P2. E-G. Illustration (E) and photo (F) for color shift of the CE from P3 to P8. G shows zoomed view of the CE revealing appearance of ommatidial units at different stages, including dotted (P3, P4), then hexagonal (P5-7) and finally, a filled pattern (P8-eclosion). $\mathrm{H}$-I. Black triangles indicate a slightly tanned suture at forewing-tegula junction $(\mathrm{H})$ at P3, and between the mesepisternum and mesocoxa (I) at P7. Teg, tegula; Fw, forewing; Msetm, mesepisternum; Msc, meso-coxa. Scale bar unit: mm 


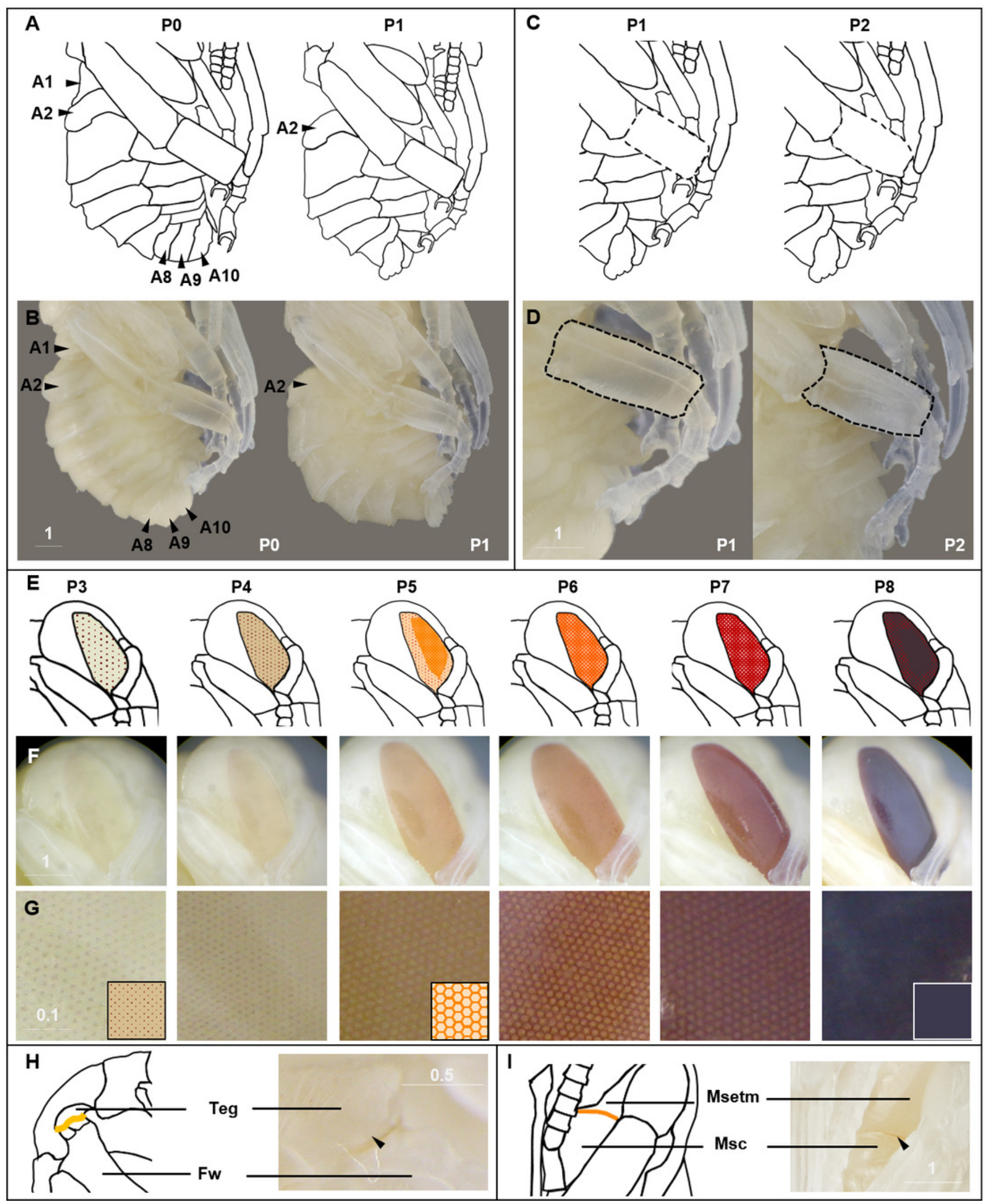


Figure 4

Morphological criteria marking the transition to P9.

$A \& B$ : the black triangle indicates the tanned suture in the lateral posterior thorax. $C \& D$ : the black triangle indicates a slightly tanned tarsal claw. Sct, scutum; Stm, scutellum; Tc, Tarsal claw. Scale bar unit: $\mathrm{mm}$

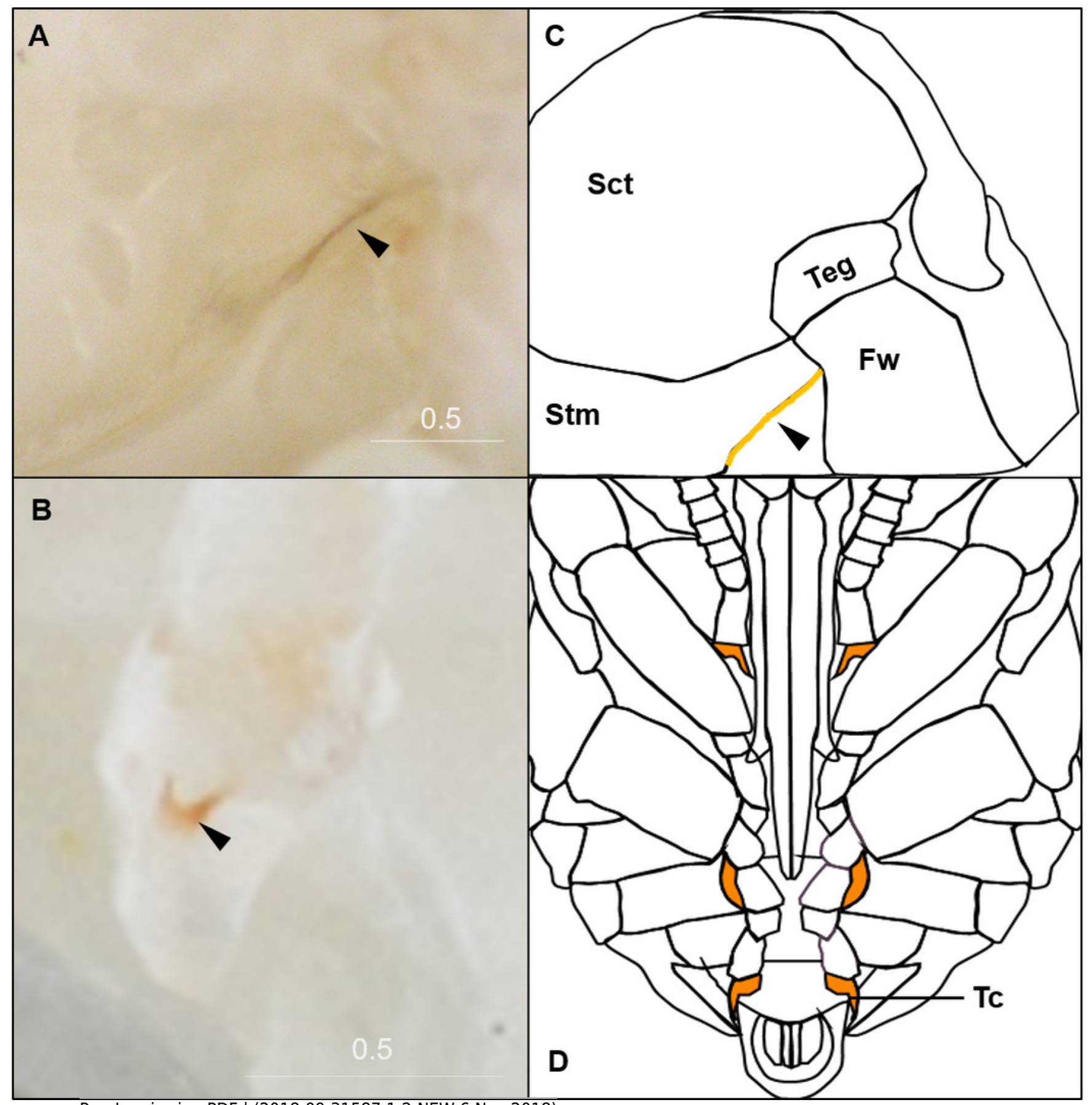




\section{Figure 5}

Morphological criteria marking the transition to P10-P16.

$A \& B$. Photo and schematic illustration of melanization patterns of abdominal cuticle.

Melanization first appears as peppered stripes on the apical margin of each metasomal tergite/sternite disc (P10-P12L), then expands anteriorly to cover the whole disc (P13-P16). The orange tinge at P12L/P13 demonstrates the beginning of tanning of the cuticle. Orange at P14-P16 indicates partial pigmentation of black setae at A3-6, while the white in T2 (P1416) indicates the white color of the future yellow hairs, as the underlying cuticle at these stages is mostly or all black. C\&D: Photo and schematic illustration of pigmentation on the head region including the face, mouthparts and antennae. $\mathrm{Mb}$, mandible; Th, teeth; $\mathrm{Fl}$, frontal line; Sp, Scape; Lb, labrum; Pb, proboscis; Pa, paraocular area; Clp, clypeus; Pd, pedicle; Fg, flagellomeres; Pbl, lateral-basal proboscis. Black triangle: broken melanization stripes at stage P11. Scale bar unit: $\mathrm{mm}$ 


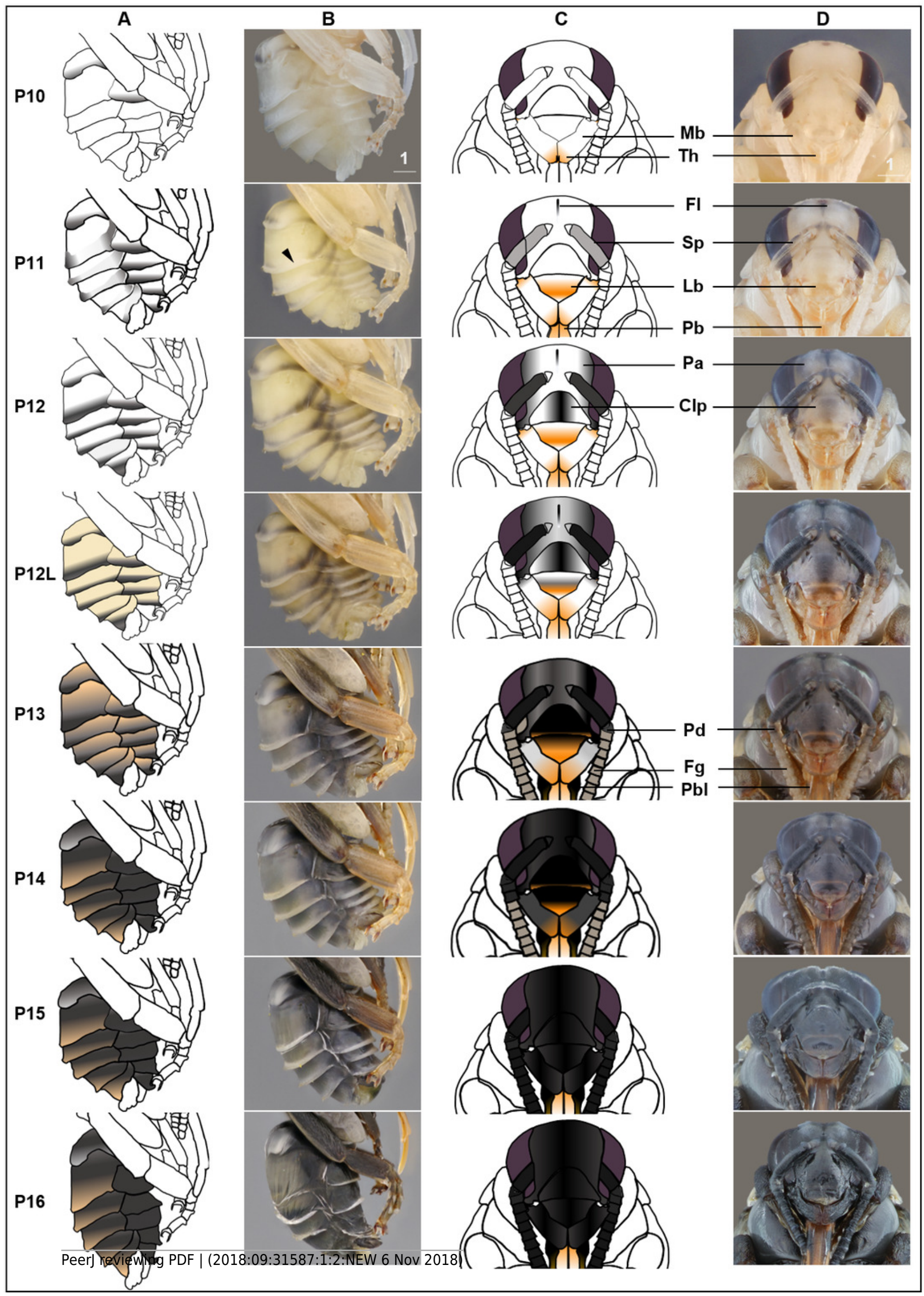




\section{Figure 6}

Temporal changes in setal color in pupal (A) and callow (B) stages.

For A. Metasomal setal color development at late pupal stages of $B$. impatiens visible upon removal of the pupal cuticle. For B. Prospective yellow, black and red hairs are indicated by yellow, black and red arrows, respectively. Note the shift in setal color as the callow gets older, as well as the difference between yellow, black and red setae in the timing of pigmentation. Yellow setae appear to be white until 24-48 hour after eclosion, when black and red hairs are nearly fully pigmented. 


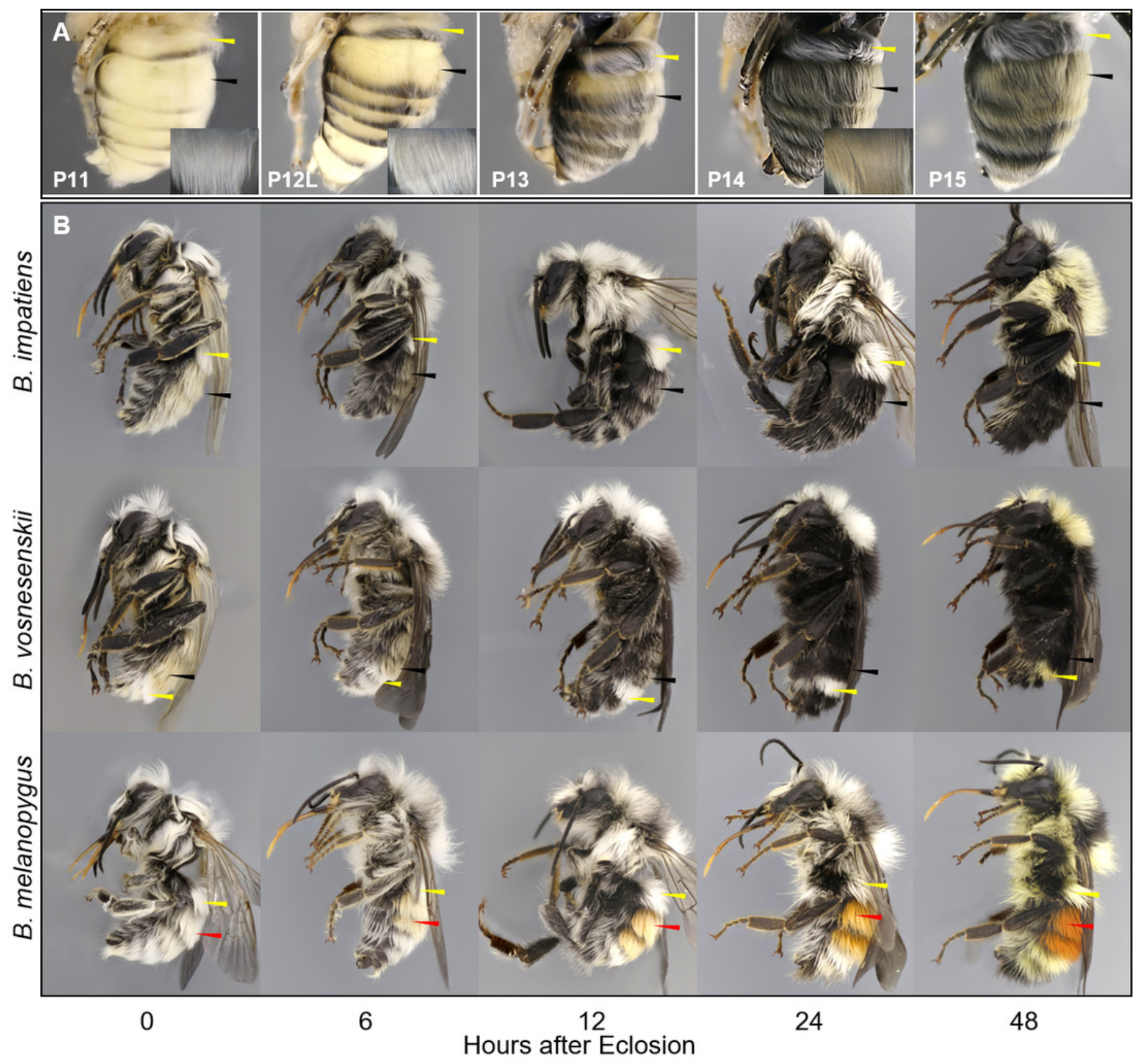


Figure 7

Photographic guide to developmental stages of $B$. impatiens male pupa.

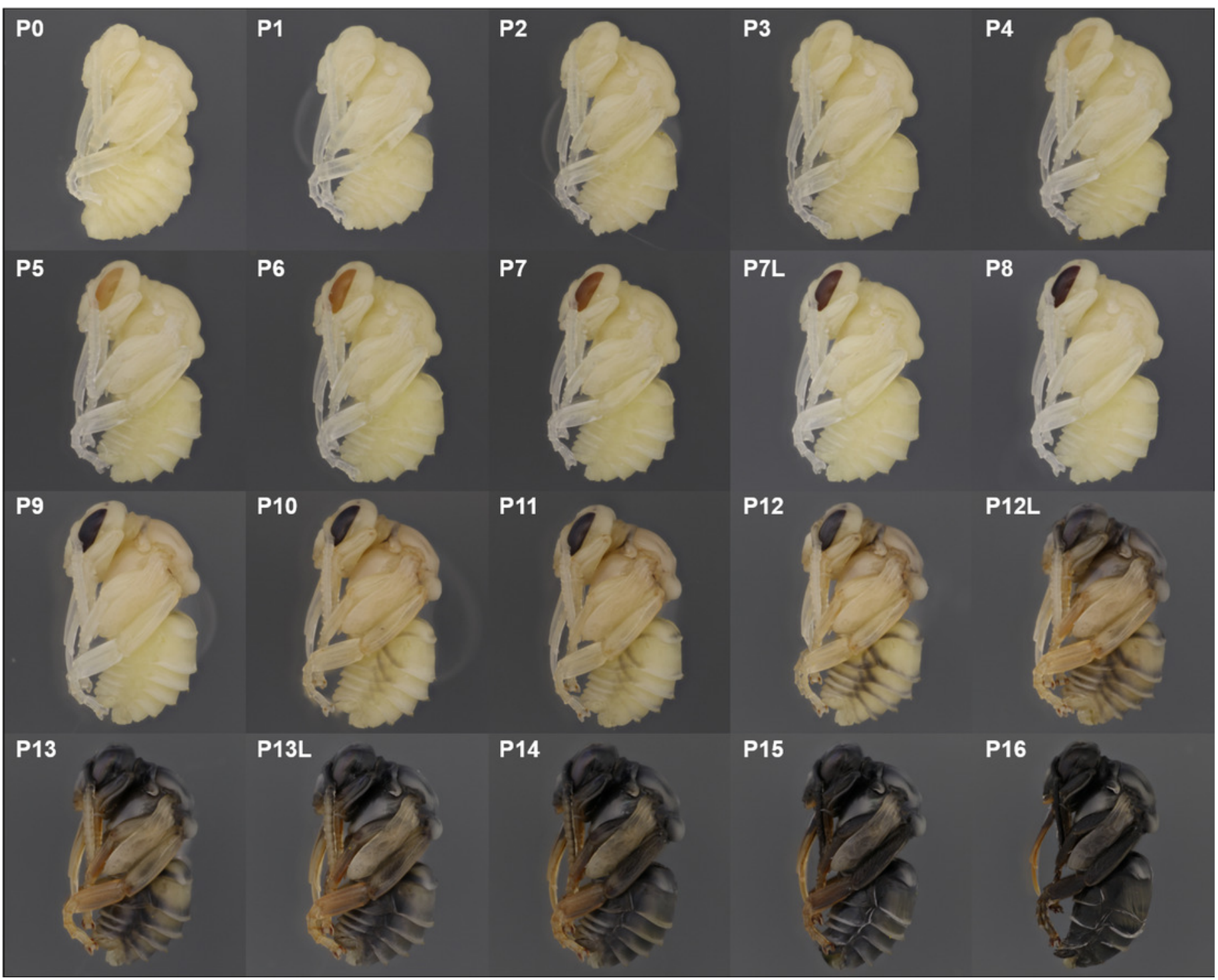




\section{Figure 8}

Variation in timing of melanization among body parts in $B$. impatiens males.

Relative darkness=grey value of measured area/255*100\%. The dotted lines indicate background darkness value of the white body, above which the tanning is visible.

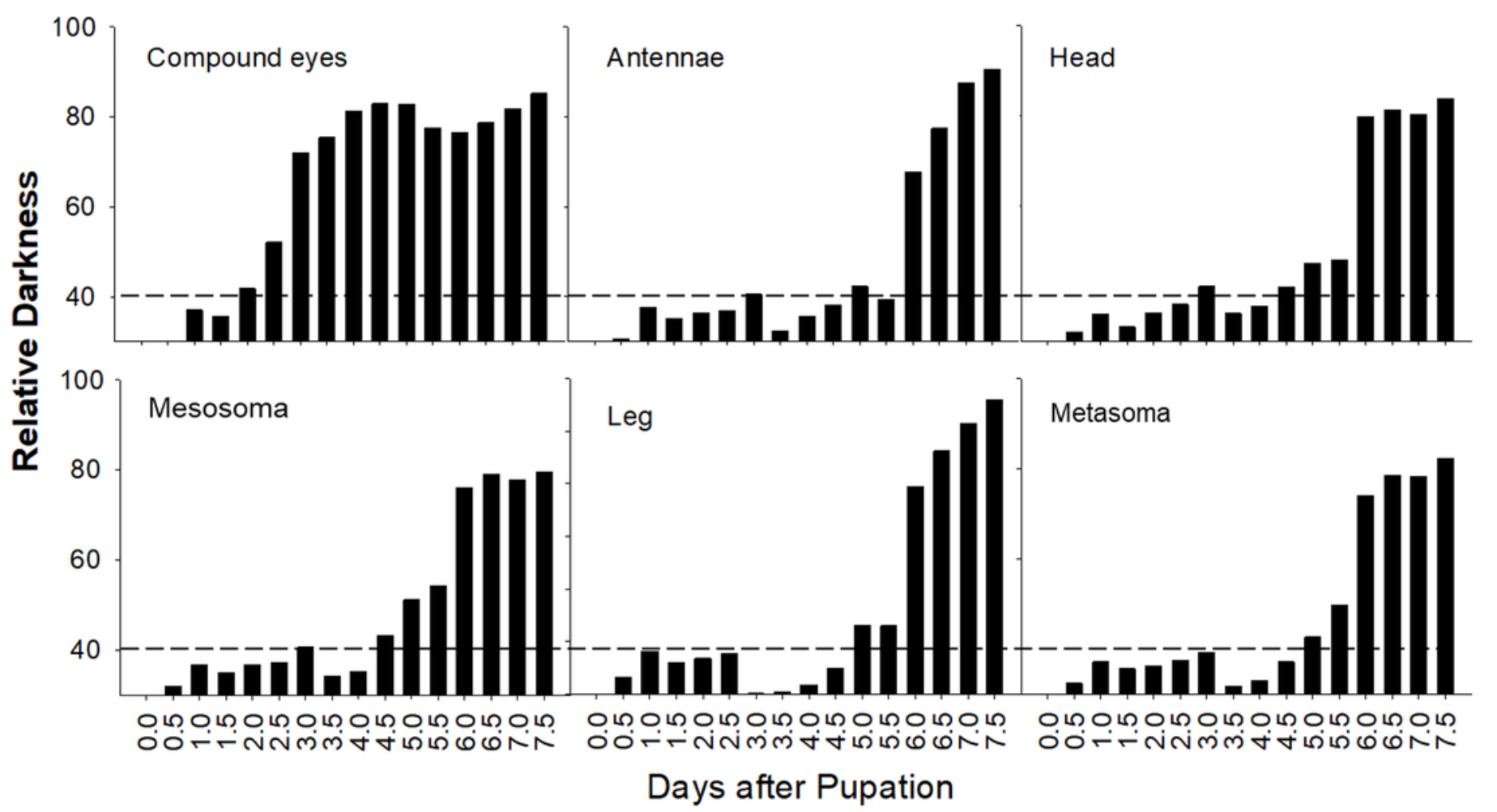


Figure 9

Summary of stage duration and pigmentation changes in B. impatiens worker pupae and callows.

Colored bars illustrate timing of pigmentation on different body parts. Bumble bee pupal staging applying the honey bee criteria (Rembold, Kremer \& Ulrich, 1980) is compared to the newly developed staging system. Details on the timing of bumble bee stages relative to the honey bee are provided in Table S2.

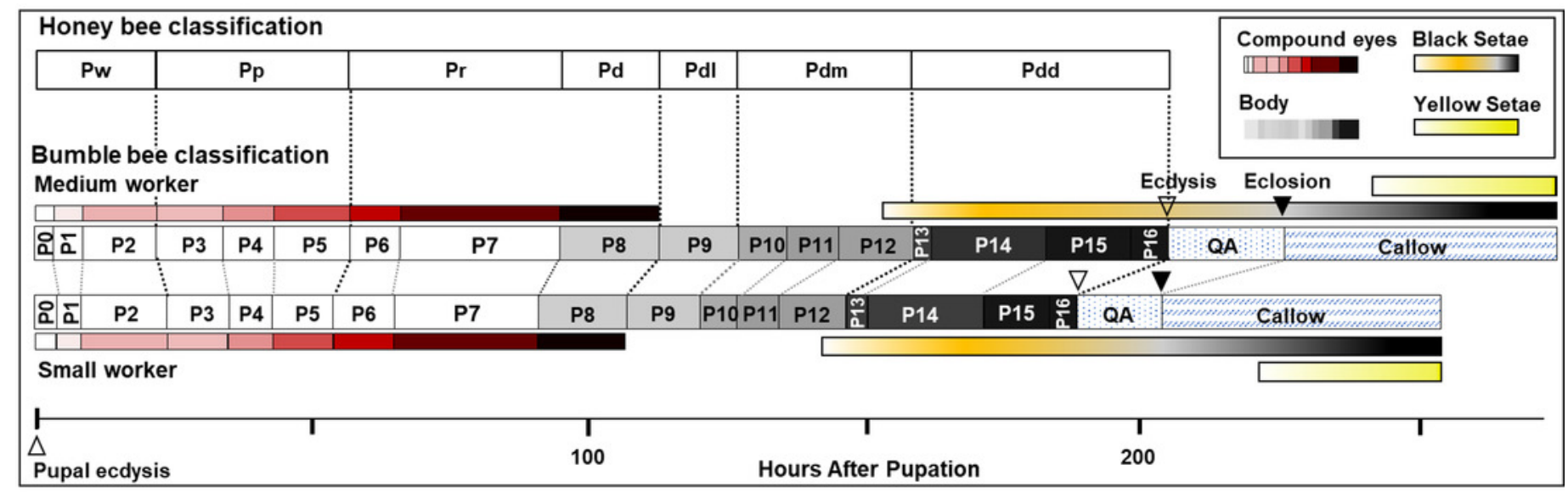




\section{Figure 10}

Bumble bee pupal duration.

A. B. impatiens pupal duration of various castes and body sizes reared at two different temperatures. B. Pupal duration of $B$. impatiens and $B$. vosnesenskii male pupae reared at different temperatures. S-W, M-W, L-W, small, medium and large workers, respectively; S-M, M-M, small and medium males, respectively. Q, queen. Error bars are standard error of the mean (SE). Means with the same letter are not significantly different, One-way ANOVA followed by Tukey's HSD post hoc test, $p<0.05 ; * p<0.05$, two-sample t-test.

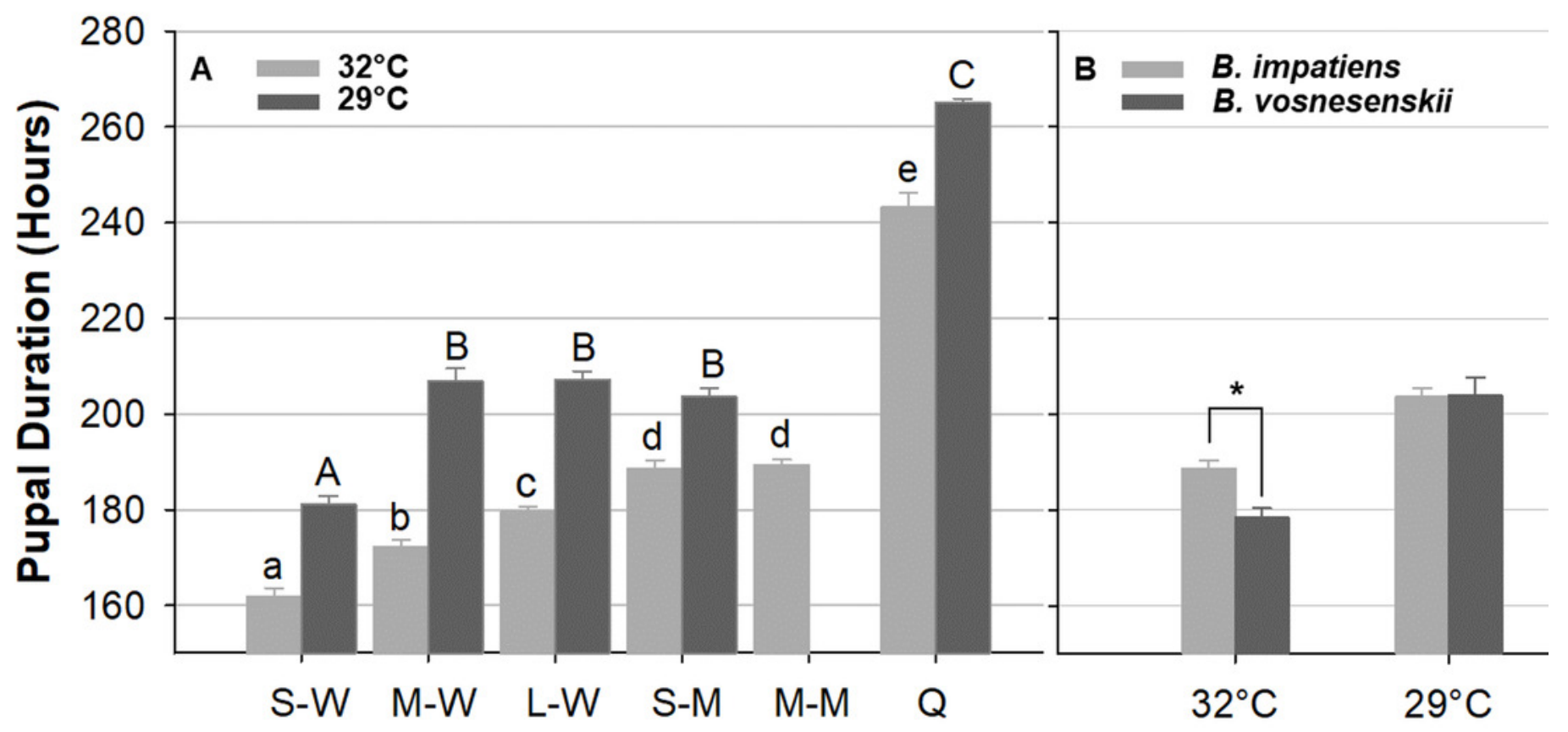

